\title{
PRODUCTIVIDAD EN CHILE: DETERMINANTES Y DESEMPEÑO*
}

\author{
Rodrigo Vergara
}

\begin{abstract}
El objetivo de este trabajo es hacer un análisis de los determinantes de la productividad en Chile en las últimas cuatro décadas. En base a ello se discuten las fortalezas y debilidades que existen en esta materia. El crecimiento de la productividad en Chile en estos años ha sido muy volátil y ha estado fuertemente correlacionado con el ciclo económico. Para retomar el proceso de crecimiento — se sostiene en este trabajo- es necesario enfatizar reformas que permitan lograr mejorías en aquellas variables que tienen un efecto significativo en la productividad y en los cuales el país hoy está relativamente más débil.
\end{abstract}

Rodrigo Vergara. Economista de la Universidad Católica de Chile y Ph. D. en economía de la Universidad de Harvard. Profesor titular del Instituto de Economía, Universidad Católica de Chile.

* Una parte importante de este artículo corresponde a una actualización y síntesis de un estudio sobre productividad en Chile realizado para la Organización para el Desarrollo Industrial de las Naciones Unidas (UNIDO).

El autor agradece la valiosa ayuda de investigación de María Elena Arzola. 


\section{Introducción}

ت

l objetivo de este trabajo es hacer un análisis de los determinantes de la productividad en Chile en las últimas cuatro décadas. En base a ello se discuten las fortalezas y debilidades que existen en esta materia.

El artículo se divide en cuatro secciones. Luego de esta introducción, en la sección 2 se analiza la evolución de la productividad en Chile en las últimas cuatro décadas. Se divide el período en quinquenios y se entrega una interpretación de los subperíodos de aceleración y desaceleración de la productividad, a la vez que se presentan correlaciones entre el ciclo económico y los ciclos de productividad. En la sección 3 se examinan los principales determinantes de la productividad y cuál ha sido el rol de cada uno de estos elementos para el caso de Chile. En base a ello se determinan las fortalezas y debilidades de Chile en materia de incrementos de productividad. Finalmente, las conclusiones son presentadas en la sección 4.

\section{Evolución de la PTF en Chile: 1960-2004}

El Cuadro $N^{\circ} 1$ presenta la evolución de la productividad total de los factores (PTF) en Chile por quinquenio entre 1960 y 2004. La PTF se ha medido como el residuo entre el crecimiento del PIB y la contribución del capital y el trabajo al crecimiento ${ }^{1}$. Se observan al menos dos patrones. En primer lugar, la PTF en Chile es bastante volátil. Tiene períodos de fuerte alza como en 1966-1970, 1976-1980 y 1986-1995, a la vez que es negativa en 1971-1975 y 1981-1985. En segundo lugar, tal como era esperable², la PTF es altamente procíclica. De hecho el coeficiente de correlación entre el crecimiento del PIB y el de la PTF es 0,91. En términos generales períodos de alto crecimiento del PIB van acompañados de períodos de alto crecimiento de la PTF. Quizás el único subperíodo donde se podría decir que hay una leve excepción es en 1986-1990, en que la economía tuvo un alto crecimiento pero el factor que más contribuyó no fue la PTF sino el trabajo ${ }^{3}$. A la inversa, en los períodos de recesión la PTF tiene una tasa de crecimiento negativa.

${ }^{1}$ Las participaciones del capital y trabajo son 0,55 y 0,45 , respectivamente. Las horas trabajadas y el stock de capital se obtienen de cifras del Ministerio de Hacienda (2004). Para más detalle sobre las fórmulas de cálculo, véase Vergara y Rivero (2005).

2 Beyer y Vergara (2002).

3 Debe recordarse que, en ese entonces, se venía de altas tasas de desempleo producto de la crisis de 1982-1983. 
CUADRO N ${ }^{\circ}$ 1: $\quad$ EVOLUCIÓN PTF

\begin{tabular}{lc|rcc}
\hline \multirow{2}{*}{$\begin{array}{l}\text { Período } \\
\text { Crecimiento } \\
\text { PIB (\%) }\end{array}$} & \multicolumn{3}{c}{ Contribución (\%) de: } \\
\cline { 3 - 5 } & PTF & Trabajo & Capital \\
\hline $1961-1965$ & 3,8 & 1,3 & 0,7 & 1,7 \\
$1966-1970$ & 4,7 & 3,1 & 0,0 & 1,6 \\
$1971-1975$ & $-2,2$ & $-3,2$ & 0,1 & 0,8 \\
$1976-1980$ & 7,5 & 5,1 & 2,1 & 0,4 \\
$1981-1985$ & $-0,7$ & $-2,3$ & 0,9 & 0,7 \\
$1986-1990$ & 6,7 & 2,1 & 3,2 & 1,5 \\
$1991-1995$ & 8,7 & 4,9 & 1,1 & 2,8 \\
$1996-2000$ & 4,2 & 0,9 & 0,3 & 3,0 \\
$2001-2004$ & 3,8 & 1,0 & 0,7 & 2,1 \\
\hline
\end{tabular}
del INE.

Fuente: Estimaciones propias con base en datos oficiales del Banco Central y

CUADRO N ${ }^{\circ}$ 2: $\quad$ PTF AJUSTADA POR CALIDAD DE LOS FACTORES

\begin{tabular}{lc|rcr}
\hline \multirow{2}{*}{ Período } & \multirow{2}{*}{$\begin{array}{c}\text { Crecimiento } \\
\text { PIB (\%) }\end{array}$} & PTF & Trabajo & Capital \\
\cline { 3 - 5 } & 3,8 & $-0,2$ & 2,2 & 1,8 \\
$1960-1965$ & 4,7 & 1,8 & 1,3 & 1,6 \\
$1966-1970$ & $-2,2$ & $-4,6$ & 2,4 & $-0,1$ \\
$1971-1975$ & 7,5 & 4,9 & 1,3 & 1,4 \\
$1981-1985$ & $-0,7$ & $-3,4$ & 2,3 & 0,3 \\
$1986-1990$ & 6,7 & 1,9 & 2,6 & 2,2 \\
$1991-1995$ & 8,7 & 3,5 & 2,9 & 2,2 \\
$1996-2000$ & 4,2 & 0,2 & 1,2 & 2,8 \\
$2001-2004$ & 3,8 & 0,4 & 1,3 & 2,2 \\
& & & & \\
\hline
\end{tabular}
del INE.

Fuente: Estimaciones propias con base en datos oficiales del Banco Central y

En el Cuadro No 2 se hace una medición alternativa de la PTF, corrigiendo por calidad y uso de los factores productivos. El capital se corrige por su tasa de utilización usando para ello la tasa de desempleo, y el trabajo por su calidad, empleando para ello el nivel de escolaridad ${ }^{4}$. Los resultados son algo distinto a los anteriores en cuanto la contribución de la PTF se reduce, aunque sigue siendo clave. Las dos conclusiones anteriores se

${ }^{4}$ Estos ajustes son los que hace el Ministerio de Hacienda de Chile (2004) cuando calcula el PIB potencial. 
mantienen: la PTF es volátil y está fuertemente correlacionada con el comportamiento del PIB.

En los subperíodos de alto crecimiento hay diversos factores que explican el fuerte aumento de la productividad, algunos de ellos domésticos y otros externos. Los relacionados con shocks de términos de intercambio tienen probablemente un carácter más transitorio, en cuanto dichos shocks son por naturaleza transitorios. Por ejemplo, en 1966-1970 se produce un fuerte incremento del PIB y también de la productividad. Se trata de un período en que los términos de intercambio presentaron niveles récord. El cobre, que en ese entonces representaba un $80 \%$ de las exportaciones chilenas, tuvo su mayor precio en términos reales en 50 años. En 1966 se alcanzó el máximo anual, lo que coincidió con la mayor tasa de crecimiento del PIB (13,6\%). Los mayores términos de intercambio se tradujeron en un aumento del ingreso y de la demanda agregada. Esta mayor demanda tiene un impacto en el PIB y en la productividad, al menos en el corto plazo. El segundo período de alto crecimiento (1976-1980) se caracteriza por dos hechos. El primero es la recuperación de las recesiones de 1973 y 1975. El segundo es el inicio de las reformas económicas en Chile, orientadas a transformar la economía en la línea de una economía abierta y de mercado. Los resultados iniciales fueron impresionantes y la economía creció 7,5\% en promedio durante dicho período.

Por cierto, el período termina con la crisis de 1982-1983, la peor recesión desde la Gran Depresión, en que el PIB se contrajo 15\% y la tasa de desempleo llegó a $30 \%$ de la fuerza de trabajo. Uno de los factores que explica esta recesión es la recesión internacional y la crisis de la deuda en América Latina. Así, el fuerte aumento en la tasa de interés en Estados Unidos, con el fin de controlar la inflación, tuvo devastadores efectos en la región y en Chile. Sin embargo, también hay factores domésticos que juegan un rol importante. Entre ellos cabe mencionar una supervisión y regulación deficiente del sistema bancario, que significó la caída de una parte importante de ellos durante la crisis y que profundizó dicha crisis. Otro factor importante fue la masiva apreciación de la moneda con los consecuentes déficits en cuenta corriente (14,5\% del PIB en 1981).

El siguiente período de alta productividad se inicia a mediados de los 80 y dura hasta la segunda mitad de los 90 . En la literatura este período se ha denominado "el período de oro de la economía chilena", ya que el PIB creció sobre $7 \%{ }^{5}$ y la pobreza se redujo de más de $40 \%$ de la población en 1987 a alrededor de 20\% una década más tarde. Básicamente éste es un

${ }^{5}$ Gallego y Loayza (2002). 
crecimiento derivado de factores domésticos. En este período maduran las reformas que se habían iniciado en los 70, se profundizan y se complementan con otras reformas y se corrigen los errores previos. Todo ello en un contexto en que el país volvía a la democracia luego de 17 años.

Una de las lecciones que se extraen de la experiencia chilena es que la perseverancia es clave. Muchas veces las reformas toman tiempo en rendir frutos. Es probable que esto se deba, entre otras cosas, a que en el camino se cometen errores. Pero es clave la persistencia. En el caso de Chile, si luego de la crisis de 1982-1983 se hubiera abandonado la política de economía libre y abierta al exterior, es probable que el boom posterior nunca se hubiera producido.

El período de elevado crecimiento, no obstante, llega a su fin en la segunda mitad de los 90 . Hay un claro freno de la productividad 6 . Beyer y Vergara (2002) argumentan que hay un agotamiento de las reformas y que no se produjeron a tiempo las nuevas reformas necesarias para dar un nuevo impulso a la economía. Lo cierto es que desde 1998 el crecimiento promedio del PIB ha sido 3,2\% y la PTF ha aumentado apenas 0,5\%. Sólo a partir de 2004, y luego de un fuerte incremento de los términos de intercambio, Chile ha retomado altas tasas de crecimiento. No obstante, parece haber un consenso que se trata de algo transitorio y que el crecimiento potencial ha cambiado sólo marginalmente ${ }^{7}$.

Los períodos de crecimiento negativo son 1971-1975 y 1981-1985. El primero tiene que ver con el experimento populista de la Unidad Popular, en el cual se mezcló un elevado déficit fiscal, inflación descontrolada y fuerte intervención estatal (con masivas estatizaciones), que finalmente se tradujeron en una crisis económica de la cual fue difícil salir. El ajuste de 1975, que además coincidió con una fuerte caída de términos de intercambio dicho año, se tradujo en una caída de $14,5 \%$ del PIB. El segundo período de crecimiento negativo tiene que ver con la crisis de 1982-1983 ya comentada.

Utilizando datos de las Naciones Unidas, Vergara (2005) estima la evolución de la productividad laboral en Chile vis-à-vis la de Estados Unidos en 1961-2000. En 1961 la productividad del trabajo en Chile era un 39,5\% de la de Estados Unidos y el 2000 fue de 38,9\%. Esto significa que la relación se ha mantenido relativamente estable en este período. Esto no es un buen resultado para un país de ingreso medio que pretende alcanzar el nivel de los líderes.

\footnotetext{
${ }^{6}$ Vergara (2004).

${ }^{7}$ El Banco Central de Chile (2005) estima un PIB potencial que crece en $4 \%$ en 2004 y que crecería algo más en los años venideros, producto del fuerte incremento de la inversión en capital fijo a partir de dicho año.
} 
La razón de este desempeño tan pobre es el mal desempeño durante la primera parte del período analizado, que se compensó con una mejora hacia la segunda parte. Las reformas básicas a la economía chilena comenzaron a implementarse a mediados de los 70 y sus frutos comenzaron a aparecer a mediados de los 80 . Desde ese momento la economía chilena inició el proceso de convergencia hacia las economías líderes. La productividad media del trabajo en Chile se incrementó en promedio 0,9\% anual durante 1962-1985 y en un 3,8\% durante 1986-2000 (Cuadro № 3).

Desde mediados de los 80, las tasas de crecimiento de la productividad del trabajo son significativamente más altas que las de los países del mundo desarrollado, por lo tanto ya existe una trayectoria hacia la convergencia. Si esta trayectoria se mantiene durante una o dos décadas, la brecha de productividades con Estados Unidos se volverá cada vez menor.

CUADRO N ${ }^{\circ}$ 3: $\quad$ CRECIMIENTO DE LA PRODUCTIVIDAD MEDIA DEL TRABAJO (PMeL)

CHILE: $1962-2000$

\begin{tabular}{lc}
\hline Período & Crec. PMeL \\
\hline $1962-1985$ & 0,9 \\
$1985-2000$ & 3,8 \\
$1962-2000$ & 2,1 \\
\hline
\end{tabular}

\section{Principales determinantes de la productividad}

El propósito de esta sección es establecer las fortalezas y debilidades del país en los siguientes cinco grupos de determinantes de productividad:

1. Creación, transmisión y absorción de conocimiento.

2. Oferta y asignación de factores.

3. Instituciones e invariantes.

4. Competencia, dimensión social y medio ambiente.

5. Aspectos específicos al país.

\subsection{Creación, transmisión y absorción de conocimiento}

En esta sección se pretende determinar la importancia de la investigación y desarrollo en el país. En particular, para Chile, la transferencia de tecnologías desde el exterior, que se lleva a cabo a través del comercio y la 
inversión extranjera directa, es una importante fuente de conocimiento. Por esta razón el nivel de conocimiento depende en forma directa de la capacidad de absorción de nuevas tecnologías del país: a mayor capacidad de absorción hay más probabilidad que la nueva tecnología tenga un uso productivo.

\section{1.a) Investigación y Desarrollo (ID)}

La ausencia de una política específica de ID se menciona a menudo como una de las debilidades de la economía chilena (De Gregorio, 2004). La evidencia muestra que aquellos países que destinan una mayor proporción del producto a ID tienen, en promedio, mayores tasas de crecimiento (Lederman y Maloney, 2003), pues ésta facilita la adopción de tecnologías y la producción de mejores bienes y servicios.

El Cuadro $\mathrm{N}^{\circ} 4$ muestra el Índice de Competitividad Global (ICG) del Foro Económico Mundial (FEM) para 2003 y 2004. En la última versión Chile se ubica en el lugar 22, con una de las mejores ubicaciones entre los países latinoamericanos y en tercer lugar dentro de los países en vías de desarrollo, después de Emiratos Árabes Unidos (16) y Estonia (20). Este resultado excepcional es consecuencia del buen desempeño económico del país durante los últimos 20 años. Sin embargo, es interesante destacar que Chile se ubica en una posición mucho más baja de acuerdo al Índice de Tecnología (IT), que es uno de los subíndices en base a los cuales se construye el ICG.

En dicho ranking nuestro país ocupa el lugar 32 y según el reporte del FEM una de las principales razones, como se discutirá más adelante, es la baja calidad de la educación. Otro argumento apunta a la baja inversión en ID (De Gregorio, 2004; Ministerio de Hacienda, 2004).

El Gráfico $N^{\circ} 1$ muestra el gasto en ID como porcentaje del producto para distintos grupos de países y para Chile. A partir de este gráfico se puede observar que para el año 2000 el gasto de Chile en ID $(0,5 \%)$ es menor que el promedio mundial (1,3\%), que el de los países industrializados y que el promedio para los países del Este Asiático. En 1980 el gasto (como porcentaje del PIB) en ID de Chile fue mayor que el del Este Asiático, pero en la actualidad éste lo triplica.

Si comparamos a Chile con América Latina nuestra posición es más favorable. Sólo Cuba y Brasil superan a Chile. De Gregorio (2004) concluye que, tras ajustar según PPP, el gasto de Chile en ID está cerca del promedio esperado de acuerdo al nivel de ingreso per cápita. A pesar de esto, sugiere que el país se vería más beneficiado con una mayor inversión en ID. 
CUADRO N 4: $\quad$ ÍNDICE DE COMPETITIVIDAD Y CRECIMIENTO 2004 Y 2003

\begin{tabular}{|c|c|c|c|c|c|c|c|}
\hline País & $\begin{array}{c}\text { CGI } 2004 \\
\text { Ranking }\end{array}$ & $\begin{array}{l}\text { CGI } 2004 \\
\text { Puntaje }\end{array}$ & $\begin{array}{c}\text { CGI } 2003 \\
\text { Ranking }\end{array}$ & $\begin{array}{c}\text { CG } \\
\mathrm{Ra}\end{array}$ & $\begin{array}{l}\text { I } 2004 \\
\text { nking }\end{array}$ & $\begin{array}{c}\text { CGI } 2004 \\
\text { Puntaje }\end{array}$ & $\begin{array}{c}\text { CGI } 2003 \\
\text { Ranking }\end{array}$ \\
\hline Finlandia & 1 & 5,95 & 1 & El Salvador & 53 & 4,10 & 48 \\
\hline Estados Unidos & 2 & 5,82 & 2 & Uruguay & 54 & 4,08 & 50 \\
\hline Suecia & 3 & 5,72 & 3 & India & 55 & 4,07 & 56 \\
\hline Taiwán & 4 & 5,69 & 5 & Marruecos & 56 & 4,06 & 61 \\
\hline Dinamarca & 5 & 5,66 & 4 & Brasil & 57 & 4,05 & 54 \\
\hline Noruega & 6 & 5,56 & 9 & Panamá & 58 & 4,01 & 59 \\
\hline Singapur & 7 & 5,56 & 6 & Bulgaria & 59 & 3,98 & 64 \\
\hline Suiza & 8 & 5,49 & 7 & Polonia & 60 & 3,98 & 45 \\
\hline Japón & 9 & 5,48 & 11 & Croacia & 61 & 3,94 & 53 \\
\hline Islandia & 10 & 5,44 & 8 & Egipto & 62 & 3,88 & 58 \\
\hline Reino Unido & 11 & 5,30 & 15 & Rumania & 63 & 3,86 & 75 \\
\hline Holanda & 12 & 5,30 & 12 & Colombia & 64 & 3,84 & 63 \\
\hline Alemania & 13 & 5,28 & 13 & Jamaica & 65 & 3,82 & 67 \\
\hline Australia & 14 & 5,25 & 10 & Turquía & 66 & 3,82 & 65 \\
\hline Canadá & 15 & 5,23 & 16 & Perú & 67 & 3,78 & 57 \\
\hline Emir. Árabes Unidos & 16 & 5,21 & - & Ghana & 68 & 3,78 & 71 \\
\hline Austria & 17 & 5,20 & 17 & Indonesia & 69 & 3,72 & 72 \\
\hline Nueva Zelanda & 18 & 5,18 & 14 & Federación Rusia & 70 & 3,68 & 70 \\
\hline Israel & 19 & 5,09 & 20 & Argelia & 71 & 3,67 & 74 \\
\hline Estonia & 20 & 5,08 & 22 & Rep. Dominicana & 72 & 3,63 & 62 \\
\hline Hong Kong & 21 & 5,06 & 24 & Sri Lanka & 73 & 3,57 & 68 \\
\hline Chile & 22 & 5,01 & 28 & Argentina & 74 & 3,54 & 78 \\
\hline España & 23 & 5,00 & 23 & Gambia & 75 & 3,52 & 55 \\
\hline Portugal & 24 & 4,96 & 25 & Filipinas & 76 & 3,51 & 66 \\
\hline Bélgica & 25 & 4,95 & 27 & Vietnam & 77 & 3,47 & 60 \\
\hline Luxemburgo & 26 & 4,95 & 21 & Kenia & 78 & 3,45 & 83 \\
\hline Francia & 27 & 4,92 & 26 & Uganda & 79 & 3,41 & 80 \\
\hline Bahrein & 28 & 4,91 & - & Guatemala & 80 & 3,38 & 89 \\
\hline Corea & 29 & 4,90 & 18 & Bosnia y Herzegovina & 81 & 3,38 & - \\
\hline Irlanda & 30 & 4,90 & 30 & Tanzania & 82 & 3,38 & 69 \\
\hline Malasia & 31 & 4,88 & 29 & Zambia & 83 & 3,36 & 88 \\
\hline Malta & 32 & 4,79 & 19 & Macedonia, FYR & 84 & 3,34 & 81 \\
\hline Eslovenia & 33 & 4,75 & 31 & Venezuela & 85 & 3,30 & 82 \\
\hline Tailandia & 34 & 4,58 & 32 & Ucrania & 86 & 3,27 & 84 \\
\hline Jordania & 35 & 4,58 & 34 & Malawi & 87 & 3,24 & 76 \\
\hline Lituania & 36 & 4,57 & 40 & Mali & 88 & 3,24 & 99 \\
\hline Grecia & 37 & 4,56 & 35 & Serbia y Montenegro & 89 & 3,23 & 77 \\
\hline Chipre & 38 & 4,56 & - & Ecuador & 90 & 3,18 & 86 \\
\hline Hungría & 39 & 4,56 & 33 & Pakistán & 91 & 3,17 & 73 \\
\hline República Checa & 40 & 4,55 & 39 & Mozambique & 92 & 3,17 & 93 \\
\hline Sudáfrica & 41 & 4,53 & 42 & Nigeria & 93 & 3,16 & 87 \\
\hline Túnez & 42 & 4,51 & 38 & Georgia & 94 & 3,14 & - \\
\hline República Eslovaca & 43 & 4,43 & 43 & Nicaragua & 95 & 3,12 & 90 \\
\hline Latvia & 44 & 4,43 & 37 & Madagascar & 96 & 3,11 & 96 \\
\hline Botswana & 45 & 4,30 & 36 & Honduras & 97 & 3,10 & 94 \\
\hline China & 46 & 4,29 & 44 & Bolivia & 98 & 3,09 & 85 \\
\hline Italia & 47 & 4,27 & 41 & Zimbabwe & 99 & 3,03 & 97 \\
\hline México & 48 & 4,17 & 47 & Paraguay & 100 & 2,99 & 95 \\
\hline Mauricio & 49 & 4,14 & 46 & Etiopía & 101 & 2,93 & 92 \\
\hline Costa Rica & 50 & 4,12 & 51 & Bangladesh & 102 & 2,84 & 98 \\
\hline Trinidad y Tobago & 51 & 4,12 & 49 & Angola & 103 & 2,72 & 100 \\
\hline Namibia & 52 & 4,11 & 52 & Chad & 104 & 2,50 & 101 \\
\hline
\end{tabular}

Fuente: Foro Económico Mundial. 


\section{GRÁFICO Nº 1: $\quad$ GASTO EN INVERSIÓN Y DESARROLLO (\% PIB)}

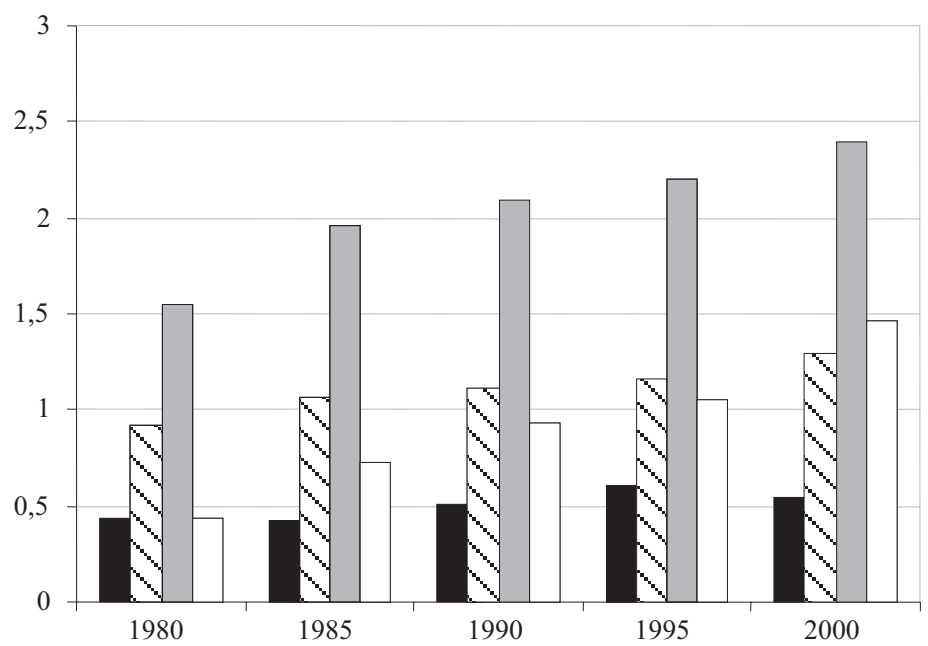

Chile Mundial $\square$ Países industrializados

Por otro lado, el gasto de Chile en ID ha crecido un 3\% por año en la última década, tasa menor que el promedio OECD (cerca de 5\% anual), a pesar del boom económico experimentado por el país y de su rápida tasa de crecimiento.

En Chile cerca del 55\% del gasto en ID es en ciencias básicas, mientras en los países del Este Asiático éste corresponde a un $20 \%$. Se supone que para un país pequeño en desarrollo es más eficiente adoptar nuevas tecnologías en vez de producirlas. Entonces el problema es que Chile está destinando demasiados recursos a las ciencias básicas, donde es más difícil obtener resultados.

El Gráfico No 2 muestra el gasto en ID, por sector que lo llevó a cabo (empresas privadas, gobierno, instituciones de educación superior e instituciones privadas sin fines de lucro) en países OECD, y el Gráfico № 3 para países en desarrollo. En los países OECD cerca del 60\% del gasto corresponde a empresas privadas y sólo un $20 \%$ al gobierno. En los países no OECD un $41 \%$ es realizado por la empresa privada y un $29 \%$ por el gobierno. En Chile la empresa privada aporta un $24 \%$, el gobierno un $30 \%$ del gasto en ID y la mayor parte corresponde a las universidades (45\%). Esto sugiere que el problema sería que en nuestro país la participación de la empresa privada en ID es muy pequeña. 


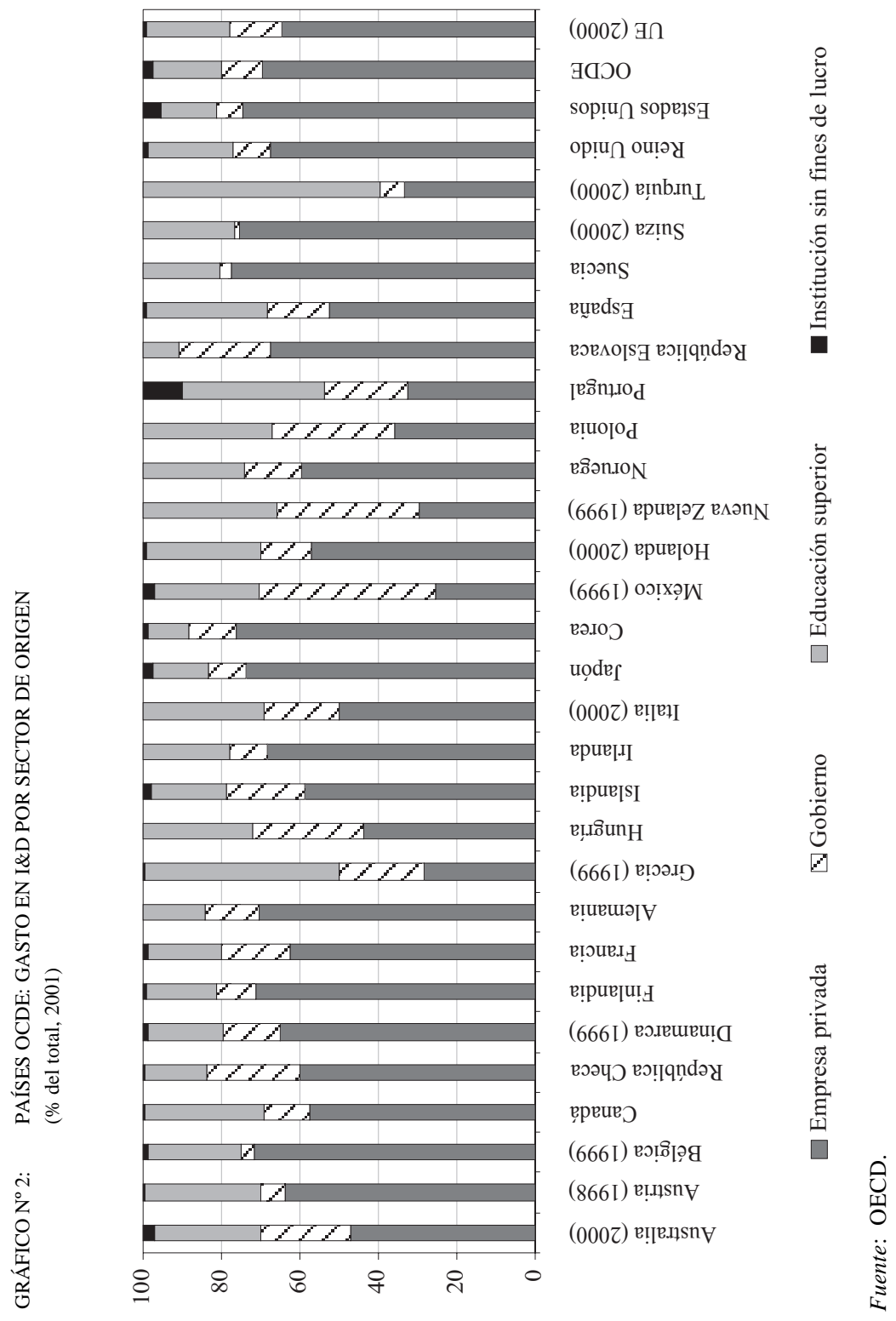




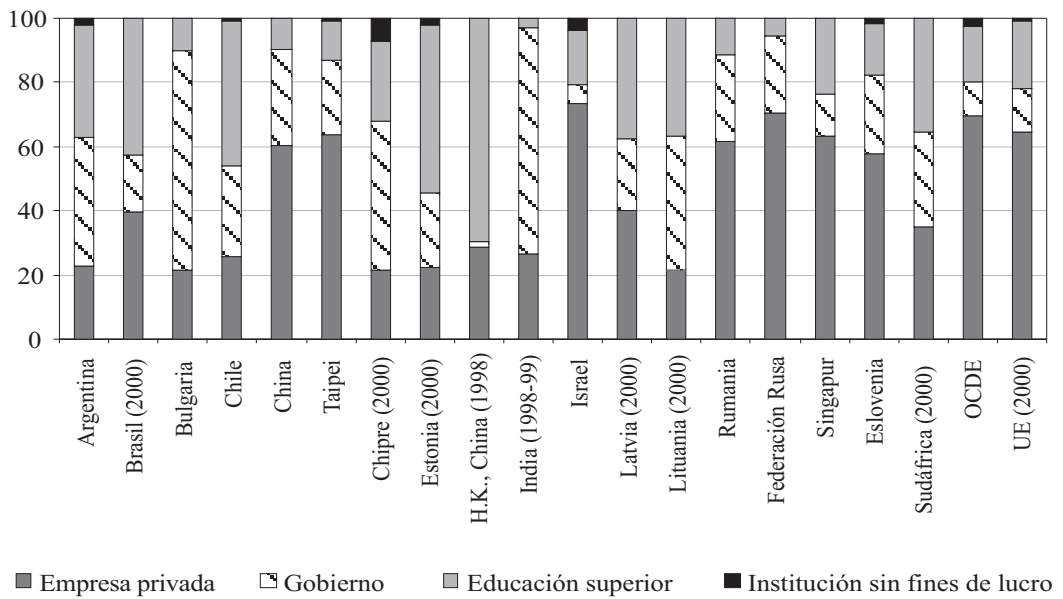

Fuente: OECD.

\section{1.b) Comercio}

Uno de los canales a través de los cuales puede transferirse la tecnología es el comercio. Los bienes y servicios contienen nueva tecnología que puede adoptarse y expandir sus efectos a toda la economía.

Dentro de las reformas ocurridas en nuestro país está la liberalización comercial ${ }^{8}$. Hacia 1970 Chile era una economía cerrada con una estrategia de sustitución de importaciones. La tarifa promedio era de 105\% y había una gran dispersión tarifaria dependiendo del tipo de bien. Además había diversas restricciones no tarifarias.

En 1974 Chile inició una estrategia unilateral de liberalización que consistió en la reducción e igualación de tarifas y en la eliminación de las restricciones no tarifarias. Hacia 1979 las tarifas habían caído a una tasa uniforme de $10 \%$. Después de la crisis de los 80 , debido a una política más proteccionista éstas se incrementaron y finalmente en 1989 alcanzaron el $15 \%$.

En 1990 las nuevas autoridades económicas decidieron continuar el proceso de reducción tarifaria, llegando a un $11 \%$ y gradualmente hasta un

${ }^{8}$ Véase Hachette (2001a) para un análisis exhaustivo de la reforma comercial chilena. 
$6 \%$ en la actualidad. Este proceso además se complementó con el desarrollo de diferentes tratados de libre comercio. Chile se embarcó en una serie de negociaciones con diferentes países o grupos de países que culminaron con importantes tratados con Estados Unidos, la Unión Europea, México, Canadá y Corea, entre otros. En la actualidad se están negociando nuevos tratados con Japón, China e India.

Estos TLC produjeron una reducción adicional en la tarifa promedio: la tarifa común es de 6\% pero es cero para la mayoría de las importaciones de los países con TLC ${ }^{9}$. Existen unos pocos productos agrícolas con mayores tarifas. De esta manera la tarifa promedio a las importaciones actualmente es de $2 \%$.

Unos de los efectos de la liberalización comercial ha sido el significativo incremento en las exportaciones, desde US\$ mil millones en 1970 a alrededor de US\$ 38 mil millones esperados para 2005.

Por otro lado, la proporción de cobre en las exportaciones totales disminuyó de un $76 \%$ en 1970 a un $36 \%$ en 2003, mientras las exportaciones industriales se incrementaron desde un $12 \%$ a un $47 \%$ del total de exportaciones.

Rojas et al. (1997) encontraron que un 80\% del incremento en la productividad total de factores en Chile en el período 1986-1996 se explica por el incremento en el comercio internacional. De Gregorio y Lee (2004) encontraron que el único y más importante factor en explicar diferencias de crecimiento entre países del Este Asiático y América Latina es la apertura comercial. Esto confirma la importancia de la apertura comercial para el crecimiento de Chile durante los últimos 20 años.

A pesar de que la participación de las exportaciones industriales se ha incrementado a lo largo de las 4 décadas anteriores, se ha criticado que la mayoría de estas exportaciones representan recursos naturales con un pequeño valor agregado ${ }^{10}$. Esto sería una consecuencia natural de la baja calidad de la educación en nuestro país, pues ayuda a impedir que se actualicen los procesos productivos.

Como se discute más adelante en este artículo, la calidad de la educación en Chile es un problema, sin embargo es cuestionable si esto es lo que está impidiendo el cambio en la mezcla productiva de nuestra economía. De hecho, el valor agregado de nuestras exportaciones se ha incrementado durante las últimas décadas y recientemente Chile se ha convertido en exportador de algunos servicios.

\footnotetext{
${ }^{9}$ Estos países representan más del 50\% del comercio exterior chileno.

${ }^{10}$ Foro Económico Mundial (2004).
} 


\section{1.c) Inversión Extranjera Directa (IED)}

Otro canal a través del cual puede transmitirse la tecnología es la Inversión Extranjera Directa. En Chile la IED fue bastante baja durante los 70 debido, entre otras razones, a la incertidumbre respecto a los derechos de propiedad. Durante los años siguientes, gracias a la implementación del DL 600 se incrementó la IED, pues éste asegura al inversionista extranjero el derecho de propiedad sobre sus inversiones en nuestro país.

El Gráfico $N^{\circ} 4$ muestra la evolución de la IED en Chile para el período 1973-2003. Entre 1997 y 2001 ésta promedió US\$ 5.500 millones anuales equivalentes a un 7,4\% del PIB.

La importancia de la IED para la absorción de nueva tecnología en Chile y su contribución a la actualización de la tecnología productiva minera, de telecomunicaciones, electricidad, industria y otros sectores ha sido evidente (Hachette, 2001 b). Actualmente más de 3.000 compañías de 60 países operan en Chile y cada vez más empresas multinacionales ven a nuestro país como el primer paso para llevar a cabo negocios con el resto de América Latina.

GRÁFICO No ${ }^{\circ}$ : INVERSIÓN EXTRANJERA DIRECTA

CHILE: 1973-2003

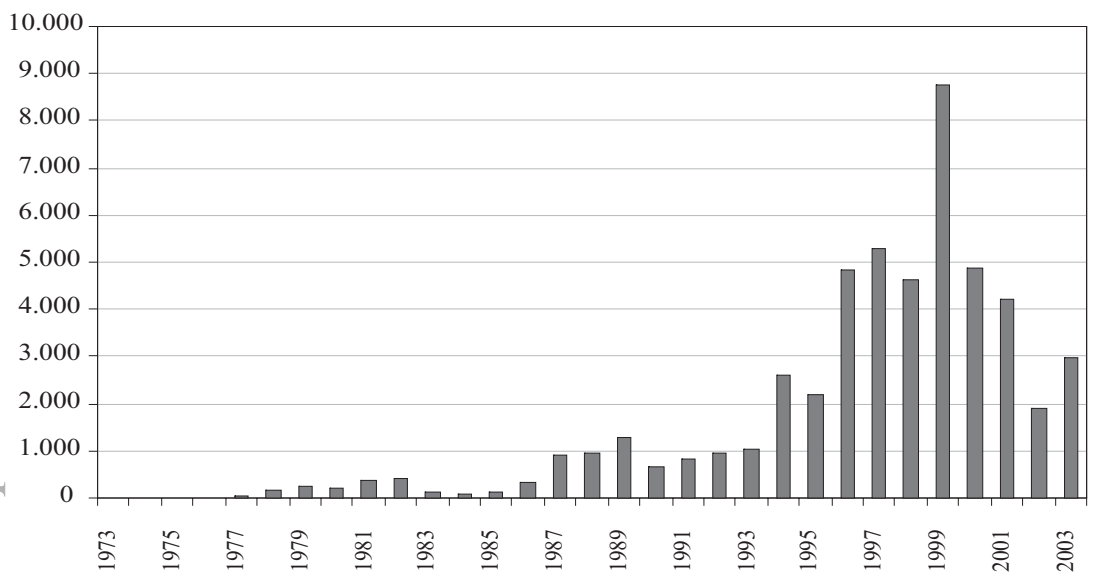

Fuente: Banco Central. 


\section{1.d) Capacidad de absorción}

Para aplicar las nuevas tecnologías a su uso productivo es fundamental la capacidad de absorción de conocimientos. Esta capacidad se relaciona en primer lugar con la calidad de la educación y, como se verá más adelante, Chile no está muy bien posicionado en este aspecto. Además se relaciona con las instituciones. Cuando las instituciones funcionan en forma apropiada las personas dedican más tiempo a las actividades productivas en vez de la búsqueda de rentas. En este contexto hay mayores probabilidades que la nueva tecnología se aplique a actividades productivas (este es el caso para todas las actividades económicas y no sólo para aquellas relacionadas a la absorción de conocimientos).

Vergara y Rivero (2005) encontraron que para Chile, durante el período 1986-2001, los sectores con el mayor crecimiento en la PTF fueron aquellos intensivos en el uso de nuevas tecnologías, lo que sugiere la existencia de una interesante capacidad de absorción de éstas.

\subsection{Oferta y asignación de factores}

\section{2.a) Inversión en capital humano (cantidad y calidad)}

En el Cuadro $\mathrm{N}^{\circ} 5$ se presentan diferentes indicadores de la calidad y cantidad de educación para un grupo de países. La primera columna muestra el promedio de escolaridad. Chile (9,9 años) se encuentra sobre el promedio para los países de América Latina, Portugal, España y Tailandia, sin embargo está por debajo de países como Irlanda, Finlandia y Nueva Zelanda. La segunda columna muestra la proporción de la población entre 25 y 64 años de edad que alcanzó a completar educación superior. Chile se encuentra marginalmente bajo el promedio de la muestra, con un $46 \%$, pero significativamente bajo los porcentajes de Irlanda, Finlandia y Nueva Zelanda. Respecto a la matrícula neta en la educación secundaria (columna 3), Chile está ligeramente bajo el promedio de la muestra, sin embargo la razón de matrícula bruta en educación terciaria es considerablemente más baja que el promedio y sólo supera a México y Brasil.

En el Gráfico $\mathrm{N}^{\circ} 5$ se muestra el gasto público en educación como porcentaje del PIB. Chile gasta 4,1\% en educación pública, porcentaje inferior al promedio OCDE pero cercano a una media amplia de países.

Respecto a la calidad de la educación, las columnas 5 a 7 del Cuadro $\mathrm{N}^{\circ} 7$ presentan algunos indicadores. La columna 5 muestra la razón de alum- 
CUADRO No 5: $\quad$ AÑOS DE ESCOLARIDAD PROMEDIO

\begin{tabular}{|c|c|c|c|c|c|c|c|}
\hline & \multirow[t]{2}{*}{$\begin{array}{l}\text { Años de } \\
\text { escolaridad } \\
\text { promedio }^{\mathrm{a}}\end{array}$} & \multirow[t]{2}{*}{$\begin{array}{c}\text { Educación } \\
\text { secundaria }^{b}\end{array}$} & \multirow[t]{2}{*}{$\begin{array}{c}\text { Tasa de } \\
\text { matrícula } \\
\text { neta en } \\
\text { educación } \\
\text { secundaria }^{\mathrm{C}}\end{array}$} & \multirow[t]{2}{*}{$\begin{array}{l}\text { Tasa de } \\
\text { matrícula } \\
\text { bruta en } \\
\text { educación } \\
\text { superior }^{d}\end{array}$} & \multirow{2}{*}{$\begin{array}{l}\text { Proporción de } \\
\text { estudiantes por } \\
\text { equipo de } \\
\text { profesores } \\
\text { educación } \\
\text { primariae }^{\mathrm{e}}\end{array}$} & \multicolumn{2}{|c|}{$\begin{array}{l}\text { Logro educacional } \\
\text { de los alumnos } \\
\text { de } 15 \text { años de } \\
\text { edad }^{\mathrm{f}}\end{array}$} \\
\hline & & & & & & $\begin{array}{c}\text { \% en el } \\
\text { nivel } 1 \\
\text { o bajo él }\end{array}$ & $\begin{array}{c}\% \text { en los } \\
\text { niveles } \\
4 \text { y } 5\end{array}$ \\
\hline Argentina & 8,3 & 42 & 81 & 57 & 22,7 & 47,7 & 11,9 \\
\hline Brasil & 7,5 & 26 & 72 & 18 & 24,8 & 67,5 & 2,6 \\
\hline Chile & 9,9 & 46 & 79 & 37 & 33,4 & 57,7 & 4,9 \\
\hline México & 8,0 & 22 & 60 & 20 & 27,0 & 51,7 & 7,0 \\
\hline Nueva Zelanda & 12,1 & 76 & 92 & 72 & 19,6 & 14,2 & 47,4 \\
\hline Dinamarca & 12,2 & 80 & - & 59 & 10,0 & 19,3 & 31,9 \\
\hline España & 9,5 & 40 & 94 & 57 & 14,7 & 20,3 & 23,0 \\
\hline Finlandia & 11,7 & 74 & 95 & 85 & 16,1 & 7,9 & 53,8 \\
\hline Irlanda & 10,2 & 58 & 82 & 47 & 20,3 & 12,7 & 41,0 \\
\hline Israel & - & - & 89 & 53 & 20,1 & 40,4 & 16,9 \\
\hline Portugal & 7,3 & 20 & 85 & 50 & 11,6 & 32,1 & 19,2 \\
\hline Tailandia & 7,5 & 38 & - & 37 & 20,4 & 49,9 & 4,3 \\
\hline
\end{tabular}

a Población entre 15 y 64 años que no estudian (2000). OCDE.

b Proporción de la población que ha alcanzado al menos los niveles altos de educación secundaria en el grupo de 25 a 64 años (2001). OCDE.

c Para 2001-2002. UNESCO.

d Para 2001-2002. Banco Mundial, 2004.

e En establecimientos públicos y privados (2001). OCDE.

${ }^{\mathrm{f}}$ Porcentaje de estudiantes en los diferentes niveles de proficiencia en la escala combinada de lectura. OCDE 2000.

Fuente: Foro Económico Mundial.

nos a profesores en educación primaria. Nuestro país, con 33,4 estudiantes por equipo de profesores, es el país con el mayor número. Esto tendría un efecto negativo en la calidad de la educación. En las columnas 6 y 7 se muestran los resultados obtenidos en la prueba PISA (Program for International Student Assessment), que realiza un test de comprensión de lectura a estudiantes de 15 años de edad. En esta prueba un 58\% de los estudiantes chilenos de 15 años están en el nivel inferior (nivel 1) o bajo éste, sólo Brasil se encuentra peor que Chile respecto a este indicador. Además (columna 7) un 4,9\% de los estudiantes están en los niveles 4 y 5, superando sólo a Brasil y Tailandia.

Chile también participó en la prueba TIMSS (Third International Mathematics and Science Study) el año 1999. En ambas pruebas los puntajes estuvieron dentro del quintil más bajo. El puntaje en la prueba de ciencias 
GRÁFICO N ${ }^{\circ}$ 5: $\quad$ GASTO PÚBLICO EN EDUCACIÓN COMO PORCENTAJE DEL PIB 1999-2000

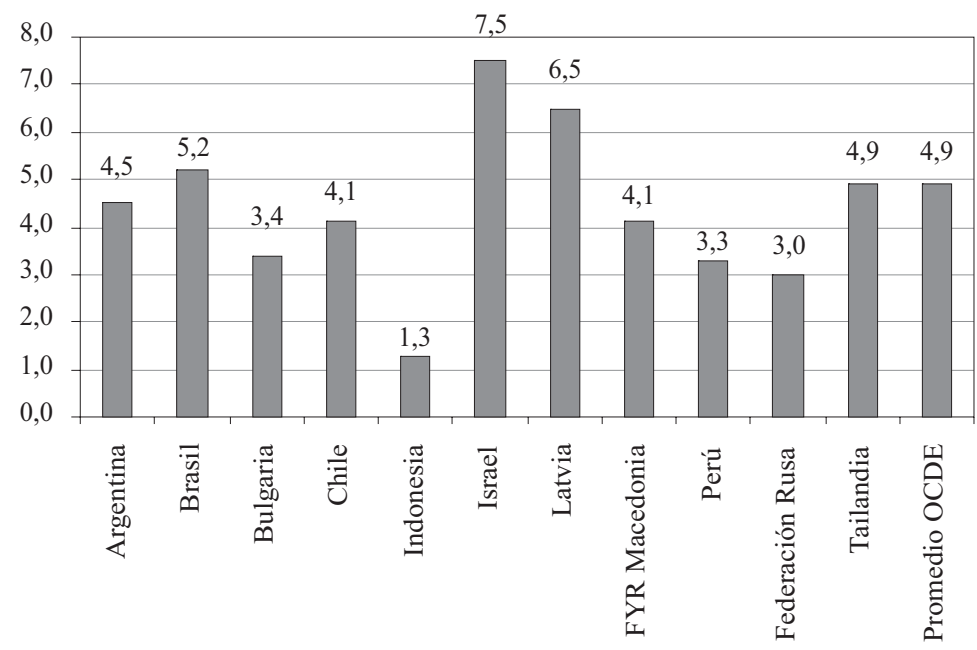

Fuente: OECD.

es $24 \%$ comparado con la media muestral de $46 \%$. Barro (1999) estimó que, dado su PIB per cápita a PPP, Chile debiera tener 43\%. Sus regresiones de crecimiento sugieren que si Chile mejora el puntaje en la prueba de ciencias al nivel proyectado de $43 \%$, aumentaría la tasa de crecimiento del PIB en $2 \%$ anual. Él señala que este resultado es demasiado grande para ser creíble, pero que evidencia la importancia de mejorar la calidad de la educación.

Barro (1999) concluye que el nivel de escolaridad en Chile está en torno a la media y por lo tanto no explica las diferencias en la tasa de crecimiento. Como variable de escolaridad él usa el promedio de años de asistencia de los hombres a los niveles secundario y de enseñanza superior, y el valor para Chile $(1,96)$ es similar al de la muestra $(1,87)$. El valor para Chile es también similar al proyectado a partir de su nivel de ingreso per cápita (1,84). Luego, la gran diferencia en el caso de Chile es la calidad de la educación.

Beyer y Vergara (2002) miden el impacto potencial de la calidad de la educación usando los datos de Barro y Lee (2000). Específicamente, ellos incorporan los datos acerca del rendimiento en la prueba de matemáticas a un modelo empírico básico de la PTF y desarrollan regresiones de corte transversal para el crecimiento promedio de la PTF durante 1980-2000 para 107 países. El indicador de calidad de la educación entra fuertemente en la 
regresión, lo que sugiere que un buen nivel educativo podría incrementar significativamente el crecimiento de la PTF. Como Chile se encuentra cerca de 11 puntos porcentuales bajo el promedio TIMSS, lograr esa meta llevaría a incrementar la PTF cerca de 0,7 punto porcentuales. Este resultado es más modesto que el de Barro, pero más creíble.

Chile tiene mucho que ganar de las mejoras en el sistema educacional. Un desempeño promedio ubicaría al país al nivel de Tailandia y Lituania y bajo países como Latvia, Malasia y Bulgaria. Ninguno de estos países tiene ingreso per cápita superior al de Chile (ajustando por PPP). Beyer y Vergara compararon los resultados de la prueba TIMSS de matemáticas con el nivel de ingreso per cápita. Chile se encuentra bajo el nivel del que debiera estar dado su PIB per cápita. En otras palabras, para un país con ese nivel de ingreso per cápita Chile debiera mostrar mejores resultados en esta prueba.

Uno de los principales factores tras el bajo desempeño de los estudiantes chilenos es que las escuelas rara vez rinden cuentas por su desempeño (Eyzaguirre y Fontaine, 2001), por esto es urgente que se reformen las instituciones educacionales. Aunque Chile financia sus escuelas a través de subvenciones, los padres no ejercen su opción de cambiar a sus hijos a mejores escuelas. Esto puede explicarse por la dificultad con que fluye la información hacia ellos. Además los resultados sobre el desempeño de los colegios están disponibles sólo a partir de 1995 y son difíciles de comprender.

Otro problema importante tiene que ver con el Estatuto Docente, que protege fuertemente a los profesores sin asignarles obligaciones claras. Bajo este estatuto es casi imposible despedir profesores aunque sus alumnos tengan un mal desempeño.

\section{2.b) Capital físico}

Chile experimentó un boom de inversión que comenzó la segunda mitad de los 80. La inversión en capital fijo se incrementó desde menos de 15\% del PIB (después de la recesión de 1982-1983) a un 27\% de PIB a mediados de los 90. Esto sitúa a Chile como uno de los países latinoamericanos con las mayores tasas de inversión, a pesar de que éstas aún son más bajas que aquellas en muchos países del Este Asiático (Larraín y Vergara, 1993). El stock de capital físico se incrementó en un factor de 2,3 entre 1980 y 2000. La recesión de 1999 hizo bajar fuertemente la inversión, pero se recupera nuevamente a partir de 2004. 
La inversión responde al entorno económico imperante. La mejora en las condiciones económicas, las leyes, la estabilidad macroeconómica, la definición de los derechos de propiedad, la eficiencia en las regulaciones (la mayoría de ellas plasmadas en las reformas económicas de las pasadas tres décadas) han sido fundamentales en explicar el incremento en la inversión en capital físico. Otros estudios (Vergara, 2004; Hsieh y Parker, 2001) también destacan la importancia de la política tributaria.

La asignación del capital físico entre sectores puede ser una medida de la flexibilidad de la economía y de cómo ésta responde a los diferentes shocks. Un argumento es que mayor flexibilidad es mejor para el crecimiento de la productividad.

Vergara y Rivero (2005) calcularon el stock de capital sectorial para los años 1986-2001. La tasa de crecimiento promedio de la acumulación de capital varió entre $2 \%$ y $4 \%$. En un período de 15 años estas tasas produjeron una significativa diferencia entre sectores.

\section{2.c) Infraestructura}

Aschauer (1989) encontró que la infraestructura pública es un importante determinante del crecimiento de la PTF. Servén y Solimano (1993) argumentan que la relación entre inversión pública y privada depende de la composición de la primera; la inversión en infraestructura probablemente fomentará la inversión privada mientras otros tipos de inversión pública tendrán el efecto opuesto. Su estimación económica sugiere que, para un panel de países en desarrollo, hay una fuerte complementariedad entre inversión pública y privada.

Calderón y Servén (2003) construyeron un índice de stock de infraestructura y uno de calidad de la infraestructura. El primero se construyó sobre la base de proxies para telecomunicaciones, generadoras eléctricas y carreteras. El segundo se basó en indicadores como el tiempo que se tarda en obtener una línea telefónica, el porcentaje de vías pavimentadas del total de vías del país y las pérdidas en la transmisión y distribución de energía eléctrica como porcentaje de la producción eléctrica total. De Gregorio (2004) usó esta información para analizar la evolución del stock de infraestructura en Chile y encontró que el crecimiento registrado durante 1970-1980 fue bajo, pero mayor que el esperado dadas las bajas tasas de crecimiento promedio del país. Para los 90 encontró que el stock se incrementó, inclusive a una tasa mayor que el promedio mundial, y que el progreso en la calidad de la infraestructura también fue mayor que el de los años anterio- 
res. De Gregorio atribuye estos cambios al incremento en la inversión pública y al gran aumento en la inversión extranjera directa en infraestructura.

Finalmente, al comparar los índices de Chile con el resto de los países se encuentra que a pesar de las mejoras sucedidas en la década anterior, nuestro país aún presenta retrasos en infraestructura respecto de países con similar nivel de desarrollo. Esto implica que el auge de inversión en infraestructura debiera mantenerse por algunos años más, hasta alcanzar niveles adecuados.

\section{2.d) Sector financiero}

La situación del sector financiero en Chile puede explicarse mediante el análisis de las tres mayores reformas que ha experimentado el país durante las décadas pasadas: la reforma bancaria, la reforma de pensiones y la reforma del Banco Central.

(i) Bancos: A mediados de los 70 se inició en Chile un proceso de liberalización financiera. Se privatizaron los bancos estatales (con excepción de uno), se liberalizaron las tasas de interés, se rebajó el encaje y se amplió el ámbito de negocios bancario.

Sin embargo, individuos que no tenían experiencia bancaria se transformaron en banqueros y al mismo tiempo en propietarios de las compañías más grandes del país. Como la supervisión era escasa ellos usaron los bancos como prestamistas de sus propias compañías.

Por otra parte, aunque se liberalizó el mercado, el gobierno se dio cuenta que debía ser él quien salvara a los clientes si algún banco quebraba. Esto ocurrió en 1977 con una quiebra bancaria masiva que el gobierno debió respaldar. Esto creó un serio problema de riesgo moral.

Al comienzo el panorama era alentador, con excepción de las altas tasas de interés reinantes. En la primera mitad de los 80 la recesión mundial y los errores en las políticas domésticas produjeron una fuerte recesión. Las ganancias de las empresas disminuyeron y se hizo cada vez más complejo pagar las deudas contraídas con los bancos. Las compañías solicitaron nuevos créditos y, como también eran propietarias de los bancos, los créditos antiguos se renovaron y se reformularon. Los depositantes continuaron entregando su dinero pues confiaban en la existencia de un seguro estatal de depósito implícito. El sistema colapsó en 1982-1983. En enero de 1983 el gobierno tomó en su poder cuatro bancos y otras cuatro instituciones fi- 
nancieras. Cerca del 50\% del crédito bancario quedó bajo control del Estado.

El costo de la crisis fue enorme ${ }^{11}$ y una de las principales lecciones que dejó fue el fortalecimiento de la supervisión/regulación bancaria. En 1986 se introdujo una nueva ley y en la actualidad la supervisión bancaria chilena es considerada una de las mejores dentro de las economías emergentes. De hecho, a pesar de la recesión de fines de los 90 el sector bancario se mantuvo fuerte.

La profundización financiera, medida a través de diferentes agregados monetarios sobre el PIB, se ha incrementado considerablemente. Por ejemplo, M3 ha aumentado de 14\% en 1970 a 48\% en 2003. Diversos índices de fortaleza en el sector financiero ponen a Chile a la cabeza de las economías emergentes ${ }^{12}$.

La fortaleza del sector bancario y la profundidad financiera son claramente algunas de las fortalezas para la productividad y al crecimiento económico. Un sistema financiero profundo y que funciona correctamente es clave para canalizar los ahorros hacia el sector productivo, pues asegura la eficiencia del proceso de inversión. Levine (2005) encuentra que a mayor profundidad del sistema financiero, mayor es la tasa de crecimiento.

(ii) Pensiones: En 1981 Chile adoptó un sistema de capitalización provisional individual en que cada persona ahorra (con un tope) un cierto porcentaje de su salario para su jubilación. Estos fondos van a una cuenta individual administrada por una compañía privada y el individuo puede mover su dinero libremente de una compañía a otra si no está conforme con la gestión. Estas empresas están debidamente reguladas y tienen límites a la composición de su portfolio (así se determina el grado de diversificación) $)^{13}$.

Los fondos de pensiones han crecido persistentemente a través de las dos décadas anteriores y en 2004 llegaron a los US\$ 58 mil millones (algo menos de 60\% del PIB, Gráfico № 6).

${ }^{11}$ Eyzaguirre y Larrañaga (1990) estimaron el costo total en cerca de un 25\% del PIB de 1990.

${ }^{12}$ Por ejemplo, en el índice de fortaleza financiera de Moody's.

${ }^{13}$ Existen al menos dos razones por las cuales es necesario regular estas compañías. Primero, los fondos corresponden a ahorro obligatorio, es decir, los individuos están obligados por ley a ahorrar en una de estas compañías para su jubilación y por lo tanto existe una responsabilidad del Estado de asegurar la administración prudente de los fondos. Segundo, hay garantías estatales explícitas. 
GRÁFICO No ${ }^{\circ}$ : $\quad$ FONDOS DE PENSIONES (\% PIB)

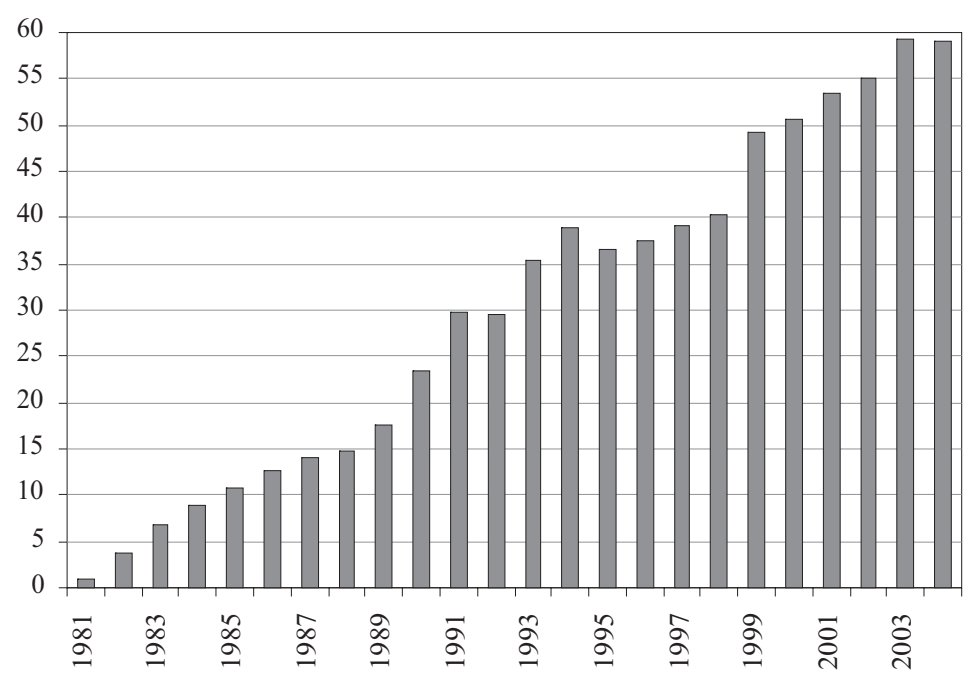

Fuente: Superintendencia de AFP.

Estos fondos han jugado un rol fundamental en el desarrollo del sector financiero chileno, en especial en el desarrollo del mercado de largo plazo. Chile es una de las pocas economías emergentes que tiene un mercado de largo plazo en su propia moneda y donde se transan bonos de 20 años o más y hay un mercado hipotecario en moneda nacional a esos plazos. Sin el sistema de pensiones habría sido difícil lograr este nivel de desarrollo. Además, este sistema ha sido adoptado en varios países de América Latina y de Europa Oriental. No obstante, aún quedan elementos que es posible perfeccionar. Por ejemplo, los fondos de pensiones no pueden invertir más del 30\% de sus activos en el exterior, lo que no parece una restricción razonable en un mundo globalizado.

(iii) Independencia del Banco Central: Chile tenía una larga tradición de alta inflación, incluso mayor que la mayoría de los países latinoamericanos. Es por eso que en 1980 se adoptó una ley que entregaba plena independencia al Banco Central. De acuerdo a esta ley, el Consejo del banco está constituido por cinco miembros nominados por el Presidente y aprobados por el Senado. Cada uno de ellos por un período de 10 años, y cada dos 
años hay un cambio en uno de los miembros del Consejo. Los consejeros no pueden ser removidos de su posición y el Ministro de Finanzas tiene el derecho a participar en las reuniones del Consejo, pero no tiene derecho a voto.

Los logros en cuanto a la inflación del Banco Central han sido impresionantes. Después de los grandes episodios inflacionarios de los 70 (en 1973 la inflación alcanzo el 500\%) la inflación se mantuvo en el rango 20\% 30\%. En 1991 el nuevo Banco Central autónomo decidió implementar metas inflacionarias con el propósito de lograr una caída gradual y persistente en la tasa de inflación, que se ha mantenido bajo el 3\% durante los últimos 4 años. La meta de inflación, desde que hay metas de inflación en 1991, siempre se ha cumplido.

A partir del año 2000 la meta pasó a ser permanente (en vez de una meta anual) con un rango de $2 \%$ a $4 \%$. La estabilidad macroeconómica (incluida la baja tasa de inflación) es una de las mayores fortalezas de la economía chilena.

\subsection{Instituciones e invariantes}

\section{3.a) Instituciones y políticas económicas}

El crecimiento de la PTF está fuertemente ligado a la calidad de las instituciones y a las políticas económicas ${ }^{14}$. Existe consenso (Easterly 1993, Krueger 1990) en que las políticas erradas pueden afectar fuertemente al crecimiento.

Un tipo de literatura relacionada destaca el rol de las instituciones en el proceso de crecimiento (por ejemplo North, 1992). Modificar las instituciones es una tarea difícil y el impacto de ese esfuerzo es menos obvio que otras acciones de política. Sin embargo, en nuestro país existe más espacio para este tipo de mejoras. Por ejemplo, el sector educacional y la burocracia del Estado son blancos obvios de reforma, pues su impacto en el crecimiento es indirecto pero altamente significativo. Un gobierno burocrático puede entorpecer permanentemente las ganancias de eficiencia y una reforma que mejore sustancialmente la burocracia estatal puede generar un incremento continuo en la eficiencia económica del país. Lo mismo se puede decir de una reforma permanente en la calidad de la educación. La productividad se incrementará cuando los nuevos graduados entren en la fuerza laboral y el

${ }^{14}$ North (1992), Beyer y Vergara (2002). 
incremento continuará hasta que la antigua fuerza laboral sea completamente reemplazada.

Uno de los problemas asociados al trabajo empírico sobre este tema ha sido la falta de datos sobre diversas políticas e instituciones en las cuales ha habido interés. Sin embargo, durante las dos décadas anteriores diferentes organizaciones han recolectado sistemáticamente información confiable acerca de la calidad de políticas e instituciones, aunque gran parte de esa información descansa en mediciones subjetivas.

La evidencia indica que la mayoría de los países han mantenido sus instituciones por largo tiempo y éstas han cambiado en forma modesta durante el tiempo. La misma evidencia también muestra que las instituciones han afectado el desempeño económico ${ }^{15}$.

Hasta ahora se han mencionado las instituciones y las políticas económicas como un solo asunto, y aunque están relacionadas, está claro que pueden ser tratadas por separado. Para el propósito del análisis que sigue se separan. En primer lugar, el foco serán las instituciones y se examinarán aspectos tales como la burocracia, leyes, corrupción. En segundo lugar se analizarán las políticas económicas en Chile, principalmente las políticas macroeconómicas.

(i) Instituciones: El Cuadro $\mathrm{N}^{\circ} 6$ muestra el Índice de Instituciones Públicas, que forma parte del Índice de Competitividad Global del Foro Económico Mundial. Chile se ubica en el lugar 20, posición más alta que su ubicación general en el ICG (22) y en segundo lugar dentro de los países en desarrollo. Ésta es claramente una buena ubicación que muestra el buen posicionamiento del país en este aspecto. Sin embargo, no implica que aún no queden espacios susceptibles de mejorar.

Kaufmann, Kraay y Zoido-Lobatón (1999) agregaron diferentes medidas de gobernabilidad originadas a partir de distintas fuentes en seis indicadores: (i) voz y responsabilidad, que mide la capacidad de los ciudadanos para participar en el proceso eleccionario; (ii) inestabilidad política y violencia, que mide las percepciones acerca de la probabilidad de que el gobierno sea desestabilizado; (iii) efectividad del gobierno, que mide la calidad del gobierno combinando las percepciones acerca de la calidad de los servicios públicos con la independencia y competencia del servicio civil, entre otros indicadores; (iv) carga regulatoria, que mide el grado en que las políticas del país son poco amistosas con el mercado y las percepciones

\footnotetext{
${ }^{15}$ Acemoglu, Johnson y Robinson (2001).
} 
CUADRO N 6: COMPONENTES DE ICG: ÍNDICE DE INSTITUCIONES PÚBLICAS

\begin{tabular}{|c|c|c|c|c|c|}
\hline \multicolumn{2}{|c|}{$\begin{array}{l}\text { Ranking/ } \\
\text { País }\end{array}$} & \multirow{2}{*}{$\begin{array}{c}\text { Puntaje } \\
6,59\end{array}$} & \multicolumn{2}{|c|}{$\begin{array}{l}\text { Ranking/ } \\
\text { País }\end{array}$} & \multirow{2}{*}{$\begin{array}{r}\text { Puntaje } \\
4,45\end{array}$} \\
\hline 1 & Dinamarca & & 53 & India & \\
\hline 2 & Islandia & 6,58 & 54 & Ghana & 4,44 \\
\hline 3 & Finlandia & 6,48 & 55 & China & 4,39 \\
\hline 4 & Nueva Zelanda & 6,41 & 56 & Bulgaria & 4,36 \\
\hline 5 & Noruega & 6,35 & 57 & Gambia & 4,30 \\
\hline 6 & Suecia & 6,31 & 58 & Perú & 4,28 \\
\hline 7 & Reino Unido & 6,23 & 59 & México & 4,28 \\
\hline 8 & Suiza & 6,22 & 60 & Panamá & 4,26 \\
\hline 9 & Hong Kong SAR & 6,22 & 61 & Colombia & 4,25 \\
\hline 10 & Singapur & 6,21 & 62 & Turquía & 4,22 \\
\hline 11 & Alemania & 6,21 & 63 & Malawi & 4,20 \\
\hline 12 & Australia & 6,10 & 64 & Trinidad y Tobago & 4,18 \\
\hline 13 & Holanda & 6,08 & 65 & Mauricio & 4,16 \\
\hline 14 & Luxemburgo & 5,99 & 66 & Zambia & 4,16 \\
\hline 15 & Austria & 5,99 & 67 & Argelia & 4,13 \\
\hline 16 & Japón & 5,88 & 68 & Indonesia & 4,12 \\
\hline 17 & Irlanda & 5,87 & 69 & Jamaica & 4,11 \\
\hline 18 & Canadá & 5,84 & 70 & Egipto & 4,10 \\
\hline 19 & Emir. Árabes Unidos & 5,82 & 71 & Rep. Dominicana & 4,08 \\
\hline 20 & Chile & 5,77 & 72 & Sri Lanka & 4,08 \\
\hline 21 & Estados Unidos & 5,74 & 73 & Zimbabwe & 3,99 \\
\hline 22 & Bélgica & 5,71 & 74 & Rumania & 3,94 \\
\hline 23 & Portugal & 5,69 & 75 & Kenia & 3,87 \\
\hline 24 & Israel & 5,64 & 76 & Croacia & 3,86 \\
\hline 25 & Francia & 5,62 & 77 & Etiopía & 3,80 \\
\hline 26 & Estonia & 5,59 & 78 & Bosnia y Herzegovina & 3,80 \\
\hline 27 & Taiwán & 5,56 & 79 & Argentina & 3,77 \\
\hline 28 & Bahrein & 5,56 & 80 & Polonia & 3,70 \\
\hline 29 & Jordania & 5,43 & 81 & Nicaragua & 3,68 \\
\hline 30 & Malta & 5,39 & 82 & Vietnam & 3,66 \\
\hline 31 & Eslovenia & 5,28 & 83 & Mali & 3,66 \\
\hline 32 & Uruguay & 5,23 & 84 & Guatemala & 3,61 \\
\hline 33 & Chipre & 5,18 & 85 & Serbia y Montenegro & 3,61 \\
\hline 34 & España & 5,16 & 86 & Uganda & 3,61 \\
\hline 35 & Sudáfrica & 5,15 & 87 & Bolivia & 3,55 \\
\hline 36 & Túnez & 5,14 & 88 & Tanzania & 3,54 \\
\hline 37 & Hungría & 5,07 & 89 & Federación Rusa & 3,54 \\
\hline 38 & Malasia & 5,06 & 90 & Ecuador & 3,42 \\
\hline 39 & Botswana & 4,98 & 91 & Venezuela & 3,41 \\
\hline 40 & Namibia & 4,92 & 92 & Macedonia, FYR & 3,41 \\
\hline 41 & Corea & 4,81 & 93 & Angola & 3,38 \\
\hline 42 & Marruecos & 4,75 & 94 & Mozambique & 3,36 \\
\hline 43 & Lituania & 4,75 & 95 & Madagascar & 3,32 \\
\hline 44 & Grecia & 4,74 & 96 & Nigeria & 3,31 \\
\hline 45 & Tailandia & 4,71 & 97 & Ucrania & 3,29 \\
\hline 46 & El Salvador & 4,71 & 98 & Paraguay & 3,24 \\
\hline 47 & Costa Rica & 4,69 & 99 & Filipinas & 3,21 \\
\hline 48 & Italia & 4,64 & 100 & Honduras & 3,19 \\
\hline 49 & República Eslovaca & 4,64 & 101 & Georgia & 3,17 \\
\hline 50 & Brasil & 4,62 & 102 & Pakistán & 2,87 \\
\hline 51 & República Checa & 4,56 & 103 & Chad & 2,61 \\
\hline 52 & Latvia & 4,55 & 104 & Bangladesh & 2,47 \\
\hline
\end{tabular}

Fuente: Foro Económico Mundial. 
CUADRO N 7: IÍNDICE DE PERCEPCIÓN DE CORRUPCIÓN, 2003 *

\begin{tabular}{|c|c|c|c|c|c|c|c|c|}
\hline \multicolumn{3}{|c|}{$\begin{array}{l}\text { Ranking/ } \\
\text { País }\end{array}$} & \multicolumn{3}{|c|}{$\begin{array}{l}\text { Ranking/ } \\
\text { País }\end{array}$} & \multicolumn{2}{|c|}{$\begin{array}{l}\text { Ranking/ } \\
\text { País }\end{array}$} & Puntaje \\
\hline 1 & Finlandia & 9,7 & 46 & Belice & 4,5 & 91 & Yemen & 2,6 \\
\hline 2 & Islandia & 9,6 & 47 & Arabia Saudita & 4,5 & 92 & Albania & 2,5 \\
\hline 3 & Dinamarca & 9,5 & 48 & Mauricio & 4,4 & 93 & Argentina & 2,5 \\
\hline 4 & Nueva Zelanda & 9,5 & 49 & Sudáfrica & 4,4 & 94 & Etiopía & 2,5 \\
\hline 5 & Singapur & 9,4 & 50 & Costa Rica & 4,3 & 95 & Gambia & 2,5 \\
\hline 6 & Suecia & 9,3 & 51 & Grecia & 4,3 & 96 & Pakistán & 2,5 \\
\hline 7 & Holanda & 8,9 & 52 & Corea del Sur & 4,3 & 97 & Filipinas & 2,5 \\
\hline 8 & Australia & 8,8 & 53 & Belarus & 4,2 & 98 & Tanzania & 2,5 \\
\hline 9 & Noruega & 8,8 & 54 & Brasil & 3,9 & 99 & Zambia & 2,5 \\
\hline 10 & Suiza & 8,8 & 55 & Bulgaria & 3,9 & 100 & Guatemala & 2,4 \\
\hline 11 & Canadá & 8,7 & 56 & República Checa & 3,9 & 101 & Kazakhstán & 2,4 \\
\hline 12 & Luxemburgo & 8,7 & 57 & Jamaica & 3,8 & 102 & Moldova & 2,4 \\
\hline 13 & Reino Unido & 8,7 & 58 & Latvia & 3,8 & 103 & Uzbekistán & 2,4 \\
\hline 14 & Austria & 8,0 & 59 & Colombia & 3,7 & 104 & Venezuela & 2,4 \\
\hline 15 & Hong Kong & 8,0 & 60 & Croacia & 3,7 & 105 & Vietnam & 2,4 \\
\hline 16 & Alemania & 7,7 & 61 & El Salvador & 3,7 & 106 & Bolivia & 2,3 \\
\hline 17 & Bélgica & 7,6 & 62 & Perú & 3,7 & 107 & Honduras & 2,3 \\
\hline 18 & Irlanda & 7,5 & 63 & Eslovaquia & 3,7 & 108 & Macedonia & 2,3 \\
\hline 19 & Estados Unidos & 7,5 & 64 & México & 3,6 & 109 & Serbia y Montenegro & 2,3 \\
\hline 20 & Chile & 7,4 & 65 & Polonia & 3,6 & 110 & Sudán & 2,3 \\
\hline 21 & Israel & 7,0 & 66 & China & 3,4 & 111 & Ucrania & 2,3 \\
\hline 22 & Japón & 7,0 & 67 & Panamá & 3,4 & 112 & Zimbabwe & 2,3 \\
\hline 23 & Francia & 6,9 & 68 & Sri Lanka & 3,4 & 113 & Rep. del Congo & 2,2 \\
\hline 24 & España & 6,9 & 69 & Syria & 3,4 & 114 & Ecuador & 2,2 \\
\hline 25 & Portugal & 6,6 & 70 & Bosnia y Herzegovina & 3,3 & 115 & Iraq & 2,2 \\
\hline 26 & Oman & 6,3 & 71 & Rep. Dominicana & 3,3 & 116 & Sierra Leona & 2,2 \\
\hline 27 & Bahrein & 6,1 & 72 & Egipto & 3,3 & 117 & Uganda & 2,2 \\
\hline 28 & Chipre & 6,1 & 73 & Ghana & 3,3 & 118 & Costa de Marfil & 2,1 \\
\hline 29 & Eslovenia & 5,9 & 74 & Marruecos & 3,3 & 119 & Kyrgyzstán & 2,1 \\
\hline 30 & Botswana & 5,7 & 75 & Tailandia & 3,3 & 120 & Libia & 2,1 \\
\hline 31 & Taiwan & 5,7 & 76 & Senegal & 3,2 & 121 & Papua Nueva Guinea & 2,1 \\
\hline 32 & Qatar & 5,6 & 77 & Turquía & 3,1 & 122 & Indonesia & 1,9 \\
\hline 33 & Estonia & 5,5 & 78 & Armenia & 3,0 & 123 & Kenia & 1,9 \\
\hline 34 & Uruguay & 5,5 & 79 & Irán & 3,0 & 124 & Angola & 1,8 \\
\hline 35 & Italia & 5,3 & 80 & El Líbano & 3,0 & 125 & Azerbaiján & 1,8 \\
\hline 36 & Kuwait & 5,3 & 81 & Mali & 3,0 & 126 & Camerún & 1,8 \\
\hline 37 & Malasia & 5,2 & 82 & Palestina & 3,0 & 127 & Georgia & 1,8 \\
\hline 38 & Emir. Árabes Unidos & 5,2 & 83 & India & 2,8 & 128 & Tajikistán & 1,8 \\
\hline 39 & Tunisia & 4,9 & 84 & Malawi & 2,8 & 129 & Myanmar & 1,6 \\
\hline 40 & Hungría & 4,8 & 85 & Rumania & 2,8 & 130 & Paraguay & 1,6 \\
\hline 41 & Lituania & 4,7 & 86 & Mozambique & 2,7 & 131 & Haití & 1,5 \\
\hline 42 & Namibia & 4,7 & 87 & Federación Rusa & 2,7 & 132 & Nigeria & 1,4 \\
\hline 43 & Cuba & 4,6 & 88 & Algeria & 2,6 & 133 & Bangladesh & 1,3 \\
\hline 44 & Jordania & 4,6 & 89 & Madagascar & 2,6 & & & \\
\hline 45 & Trinidad y Tobago & 4,6 & 90 & Nicaragua & 2,6 & & & \\
\hline
\end{tabular}

* "El índice define corrupción como el abuso del oficio público con fines privados y mide el grado en que se percibe la existencia de corrupción entre oficiales y políticos. Los puntajes van desde 10 (completamente limpio) a cero (alta corrupción).”

Fuente: Transparency International. 
acerca de las cargas impuestas por la regulación excesiva; (v) rule of law incluye varios indicadores que miden el grado de confianza de los agentes en las reglas sociales; y finalmente, (vi) soborno, que mide las percepciones acerca de la corrupción. La selección de unidades de gobernabilidad asegura que las estimaciones de gobernabilidad tengan media cero, desviación estándar uno y un rango de valores de $-2,5$ a 2,5, donde mayor puntaje indica mejor resultado.

Beyer y Vergara (2002) construyeron un índice compuesto de gobernabilidad basado en estos indicadores para 78 países. Este índice tiene media 0,11 , desviación estándar de 0,775 , valor máximo de 1,75 y valor mínimo $-2,09$. Chile obtiene 1,031 , lo que sugiere que el gobierno ha hecho relativamente un buen trabajo. Después se incluye este índice en regresiones de corte transversal del crecimiento de la PTF y aparece con gran significancia. Los autores argumentan que a pesar del buen desempeño observado en Chile, un objetivo plausible es acortar a la mitad la distancia con el valor máximo. Esto incrementaría el crecimiento de la PTF en 0,4 puntos porcentuales. Los autores utilizan otros índices relacionados con calidad de la burocracia, que confirman sus conclusiones.

Transparencia Internacional construye un índice que mide corrupción (definida como el abuso del oficio político para obtener beneficios privados). Mide la percepción que tiene la población sobre la corrupción existente entre políticos y funcionarios públicos. Los puntajes van desde los 10 puntos (completamente limpio) hasta 0 (completamente corrupto). Chile se ubica en la posición 20, con un puntaje de 7,4 puntos (Cuadro $\mathrm{N}^{\circ} 7$ ), en mejor posición que algunos países desarrollados y como el menos corrupto entre los países en desarrollo.

Otro asunto importante que ha sido sujeto de debate es la regulación laboral. Como lo documentó Heckman y Pagés (2000), los costos de despido en Chile están entre los más elevados de América Latina. Ellos estimaron que dichos costos influyen en forma negativa y significativa en el empleo, especialmente en el empleo juvenil. El valor presente de los costos esperados de despedir a un trabajador está por sobre el promedio regional. Por eso ha habido en el país una serie de propuestas para flexibilizar el mercado laboral, apuntando a reducir los costos de contratar y despedir. Esta discusión sugiere que la regulación del mercado laboral puede verse como una debilidad de la economía chilena.

(ii) Política económica: Se ha encontrado que la estabilidad macroeconómica y, más específicamente, la baja inflación, tiene efecto positivo 
sobre el crecimiento ${ }^{16}$. Una inflación elevada produce costos que son mayores cuando la inflación es inesperada. Chile ha tenido una larga tradición inflacionaria que comenzó en 1940 y que alcanzó el peak en 1973, cuando alcanzó más del 500\%. Durante los 80 la inflación fluctuó entre 20\% y 30\% y en los 90 se redujo a un dígito y luego se situó dentro de los estándares internacionales (actualmente la meta es de 2 a 4\%). Como se mencionó en la sección 3.2, desde que se implementó esta política la inflación se ha mantenido dentro del rango.

Desde 1989, en Chile el Banco Central es independiente y su objetivo es mantener la estabilidad de precios. Los miembros del Consejo son nominados por el Presidente de la República y presentados al Senado, que puede aprobar o rechazar la nominación. Los nominados son profesionales altamente calificados. Ésta es una de las razones por las cuales el Banco Central de Chile cuenta con elevado prestigio y credibilidad.

La política fiscal chilena solía ser una de las mayores debilidades para el país. El déficit elevado y persistente se financiaba a través de creación de dinero, lo que se traducía en elevada inflación. El récord se alcanzó en 1973 cuando el déficit del gobierno central alcanzó un 11\% del producto y el del sector público no financiero de 30\% del PIB. Después de 1973 se llevó a cabo un ajuste fiscal y luego una reforma tributaria. El déficit presupuestario declinó sustancialmente y en 1976 había superávit. Con la recesión de 1982-1983 el déficit retornó, pero sus niveles aún eran más bajos que durante los 70 (el más alto fue de 4,3\% del PIB el año 1984). El gobierno tuvo un superávit nuevamente en 1987 que se mantuvo hasta el año 1998. La recesión de 1999 produjo el primer déficit en más de una década y a pesar de tener baja magnitud se mantuvo hasta 2003. En 2004 hubo un superávit de 2,2\% del PIB (Gráfico No 7). El elevado crecimiento económico y los superávit presupuestarios de 1987-1998 produjeron un descenso sustancial de la deuda pública. La deuda neta consolidada del sector público no financiero y del Banco Central, que era 50\% del PIB en 1989, cayó a 11\% del PIB en la actualidad.

Adicionalmente, en el año 2000 el gobierno implementó una política tendiente a mantener un superávit estructural de $1 \%$ del PIB para el gobierno central ${ }^{17}$. En el caso de Chile esto significa un superávit de 1\% del PIB después de ajustar por el precio de largo plazo del cobre y el ciclo de

\footnotetext{
${ }^{16}$ Fischer (1993), Barro (1997), De Gregorio (1992).

${ }^{17}$ Marcel et al. (2001).
} 
GRÁFICO N 7: $\quad$ PRESUPUESTO DEL GOBIERNO CENTRAL (\% PIB)

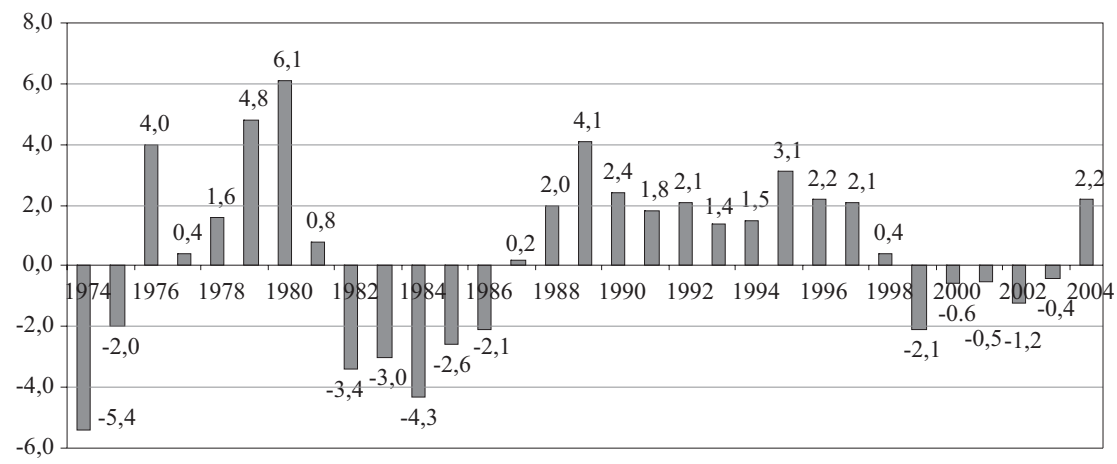

Fuente: DIPRES.

negocios (para así calcular los ingresos asumiendo que la economía está sobre la tendencia de largo plazo). En la práctica esto significa que en los años malos habrá un superávit inferior al 1\% del PIB (también puede ser déficit) y en años buenos un superávit sobre el 1\% del producto. Existen al menos dos beneficios de esta política (Vergara, 2002): en primer lugar, es una regla de sostenibilidad fiscal, y en segundo lugar, permite una política fiscal contracíclica.

El problema con el presupuesto hasta 1973 no fue sólo la falta de austeridad fiscal, sino el desorden reinante en la administración del gasto público. No había responsabilidades claras asignadas en términos de gasto y en la práctica nadie sabía qué estaba sucediendo exactamente con las finanzas públicas. En 1975 se aprobó la nueva ley orgánica de “administración financiera del Estado”. De acuerdo a ella, sólo la plana ejecutiva es responsable de proponer el presupuesto anual (estimaciones de gastos e ingresos). El Congreso no puede incrementar el gasto, sólo puede aprobar la propuesta del ejecutivo o recomendar una reducción si lo cree muy elevado. Todos los asuntos de deuda pública deben ser aprobados por la Dirección de Presupuestos y deben estar alineados con el presupuesto aprobado. Existe, además, flexibilidad en la asignación de recursos dentro de las diferentes áreas del Estado, pero existe un tope para el gasto público dado por el presupuesto. 
Este nuevo marco institucional estableció responsabilidades claras en la administración del presupuesto y dejó al gobierno el control del gasto $^{18}$.

Como conclusión se puede decir que la política fiscal actual y las instituciones relacionadas a esta política son una de las mayores fortalezas de la economía chilena.

\section{3.b) Invariantes}

Éstos se refieren a variables tales como la ubicación geográfica, la dotación de recursos naturales y el tamaño. La pregunta es cómo estas variables afectan la productividad en un determinado período de los países.

(i) Localización: La localización importa. Chile se encuentra alejado de los mercados mundiales. San Antonio y Valparaíso están a 6.300 millas de Lisboa, 11.300 de Seúl y 5.100 de Nueva York. A pesar de eso, nuestro país ha podido mantener un comercio relativamente dinámico. Por ejemplo, la estructura de las exportaciones chilenas de acuerdo al país de origen es bastante diversificada, a grandes rasgos 1/3 se dirige a Asia, 1/3 a América y 1/3 a Europa.

El factor distancia implica que para que Chile pueda competir debe contar con una excelente infraestructura (aeropuertos, puertos, telecomunicaciones, etc.). Este asunto ya se discutió y la conclusión es que a pesar del importante flujo de inversión en infraestructura, Chile todavía presenta carencias en su stock.

(ii) Tamaño: Chile es una economía pequeña. Su población es de 15 millones de habitantes y su PIB de US\$ 94 mil millones. En una economía grande las empresas cuentan con mercados más extensos para vender sus productos. Si además hay economías de escala en la producción de ciertos productos, operar en esos mercados les proporcionará una gran ventaja a las firmas. Además, el retorno a la innovación en un mercado grande es mayor.

Sin embargo, es posible enfrentar esta desventaja incorporándose a la economía mundial. Esto es, que el mercado para las empresas chilenas sea el mercado mundial. Por lo mismo, el tamaño pequeño de esta economía no puede considerarse per se una desventaja. De hecho hay muchos ejemplos de economías pequeñas tremendamente exitosas.

${ }^{18}$ Larraín y Vergara (2001). 
(iii) Dotación de recursos naturales: Se ha argumentado que la abundancia en recursos naturales es un determinante importante del fracaso económico (Sachs y Warner, 1995). Algunos autores han propuesto que la abundancia de recursos naturales puede hacer que la economía se aleje de los sectores manufactureros en los cuales existen muchas externalidades positivas para el crecimiento (Sachs y Warner, 1995). Otros autores han sugerido que al producirse auges por algún recurso en particular, éstos quedan en manos del Estado, creándose un incentivo a la búsqueda de rentas en vez de actividades productivas que soporten el crecimiento (Lane y Tornell, 1996). Rodríguez y Sachs (1999) sostienen que las economías ricas en recursos naturales crecen menos porque es probable que vivan por encima de sus posibilidades, esto significa que la economía se acerca al steady state desde arriba, mostrando tasas negativas de crecimiento en la transición.

Es difícil decir si estas ideas son ciertas para el promedio de los países abundantes en recursos naturales. La experiencia chilena muestra que ser un país abundante en recursos naturales puede ser una bendición o una maldición. La clave no es la abundancia en sí misma sino las políticas e instituciones que administren esta abundancia.

\subsection{Competencia, dimensión social y medio ambiente}

Una economía que opera en un entorno competitivo implica un extenso crecimiento de la productividad. Por otro lado, la desigualdad de ingresos puede dañar ese crecimiento, pues produce tensión social. También puede verse afectada si hay un manejo inadecuado del medio ambiente.

\section{4.a) Competencia}

A mediados de los 70 Chile cambió su política hacia una economía abierta y de libre mercado. Para esto se hizo esencial garantizar la existencia de la competencia a través de distintas reformas. Se dejó variar los precios según el mercado y se garantizó la libre entrada. El país abrió sus fronteras al comercio internacional y la competencia con el exterior contribuyó a promover la competencia interna. Además, la privatización de las compañías estatales junto con la libre entrada y el comercio internacional pusieron fin a los monopolios existentes. 
Sin embargo, la privatización de aquellas empresas que hasta ese momento eran monopolios naturales introdujo nuevos problemas y se hizo necesario elaborar ciertas regulaciones que evitaran el uso de poder monopólico y crearan condiciones apropiadas para un desempeño eficiente. Aunque está más allá del objetivo de este artículo analizar las reformas en cada sector, vale la pena mencionar que se produjo una revolución en la regulación eléctrica, telecomunicaciones, infraestructura, puertos, aeropuertos, agua, etc. Esto se suma a lo que ya se ha mencionado acerca de las reformas financiera, de pensiones, política fiscal y otras. Paredes (2001a) argumenta que en Chile, en los sectores regulados, los conceptos generales asociados a la regulación son:

(i) fuerte política antimonopolio,

(ii) libre entrada,

(iii) la no regulación como un principio,

(iv) claridad en los procedimientos,

(v) fomento de soluciones privadas a las disputas, y

(vi) autonomía de los entes reguladores.

En relación a la ley antimonopolios, hace un par de años se puso de manifiesto que ésta requería ser actualizada (Paredes, 2001b). Fue así como en 2003 una ley creó un nuevo Tribunal de la Libre Competencia compuesto por 5 miembros, en cuya nominación participan el Presidente de la República, el Banco Central y la Corte Suprema. Este tribunal, a diferencia de su antecesor, es más técnico en su naturaleza, más independiente del gobierno y con responsabilidades más claramente delimitadas.

Como en el resto del mundo, en Chile ha existido la tendencia a una mayor concentración en diferentes sectores: bancario, retail, telecomunicaciones, servicios público, etc. Aunque el tema está abierto, es probable que este proceso sea consecuencia de economías de escala generadas por el cambio tecnológico. Además, en una economía globalizada es más fácil sobrevivir con una mayor escala.

Una posible medida de eficiencia en la regulación es la disponibilidad de bienes y servicios producidos por firmas reguladas. Los diferentes índices muestran importantes avances en la provisión de esos bienes y servicios al público ${ }^{19}$.

${ }^{19}$ Véase Paredes (2001a). 
CUADRO N 8: $\quad$ DESIGUALDAD EN LA DISTRIBUCIÓN DEL INGRESO

\begin{tabular}{|c|c|c|c|c|c|}
\hline \multirow[t]{2}{*}{ Región } & \multirow[t]{2}{*}{ Gini } & \multicolumn{4}{|c|}{ Proporción de ingreso por quintil } \\
\hline & & 1 & 2 & 3 у 4 & 5 \\
\hline África sub Sahara & 0.470 & 5,2 & 8,9 & 33,5 & 52,4 \\
\hline América Latina y El Caribe & 0.493 & 4,5 & 8,7 & 33,8 & 52,9 \\
\hline Este Asiático y Pacífico & 0.381 & 6,8 & 11,3 & 37,5 & 44,3 \\
\hline Sur Asiático & 0.319 & 8,8 & 12,9 & 38,4 & 39,9 \\
\hline Europa del Este & 0.289 & 8,8 & 13,4 & 40,0 & 37,8 \\
\hline Medio Oriente y África del Norte & 0.380 & 6,9 & 10,9 & 36,8 & 45,4 \\
\hline Países desarrollados & 0.338 & 6,3 & 12,2 & 41,8 & 39,8 \\
\hline Chile & 0.565 & 3,5 & 6,6 & 28,9 & 61,0 \\
\hline
\end{tabular}

Fuente: Beyer (2000).

\section{4.b) Dimensión social}

Una de las debilidades más claras de la economía chilena es la desigualdad del ingreso. América Latina es una de las regiones del mundo con mayor desigualdad de ingresos y Chile no es la excepción. Además, dentro de América Latina Chile es uno de los países en que la desigualdad es más alta.

La desigualdad produce tensiones sociales que obstaculizan el crecimiento de la productividad ${ }^{20}$. Beyer (2000) muestra que la fuente de la desigualdad de ingresos en Chile es la desigualdad en el ingreso del trabajo y no la desigualdad de capital. Ésta es la razón por la cual la mayor parte de los estudios en esta área en Chile enfatizan el rol de la educación en explicar las diferencias de ingreso.

El Cuadro $N^{\circ} 8$ muestra diferentes indicadores de desigualdad para diferentes regiones del mundo y para Chile. Estos son el coeficiente Gini y la proporción de ingreso nacional de los diferentes quintiles de la población. América Latina posee un coeficiente de 0,49, incluso mayor que el de África sub Sahara $(0,47)$. Además es mucho más grande que los valores para los países desarrollados (0,34), Asia del Sur $(0,32)$ y Europa del Este $(0,29)$. El porcentaje de ingreso recibido por el quintil más rico en América Latina (53\%) también es el mayor del mundo, mientras el recibido por el quintil más pobre $(4,5 \%)$ es el más bajo del mundo. Chile es incluso más desigual que el promedio para Latinoamérica, su coeficiente Gini es de 56,5,

${ }^{20}$ Véase Larraín y Vergara (1992), Alesina y Rodrick (1994). 
el porcentaje de ingreso que recibe el quintil más rico es $61 \%$ y el más bajo recibe el 3,5\%.

El tema de la desigualdad está en la agenda de todos los partidos políticos más importantes del país. Existe consenso acerca de la importancia de esta variable en el crecimiento sostenible de la productividad y del producto, así como de su papel en el retraso del desarrollo.

También existe consenso acerca del papel de la educación en la reducción de la desigualdad. Como se ha señalado antes, la calidad de la educación en Chile es baja y en especial lo es para los pobres, por esto debe mejorarse para reducir la desigualdad.

\section{4.c) Medio ambiente}

Durante las últimas dos décadas ha existido en Chile una preocupación creciente por el medio ambiente. A comienzos de los 90 se introdujo el sistema de evaluación de impacto ambiental, en virtud del cual todos los proyectos de inversión importantes deben contar con un certificado ambiental. Del Fávero y Katz (2001) reconocen los avances en esta materia: en primer lugar, se ha incorporado la variable ambiental a las decisiones de inversión; segundo, ésta se ha incorporado en las etapas tempranas de los proyectos; tercero, ha estimulado la participación de las comunidades en la discusión acerca del impacto ambiental de los proyectos que a ellos les afectan; cuarto, ha inducido la coordinación entre diferentes agencias gubernamentales, y quinto, ha estimulado un nuevo mercado de estudios ambientales. Sin embargo, critican la falta de parámetros objetivos que limiten la discreción del gobierno. Además sostienen que la legislación está basada en mecanismos de control más que en mecanismos de mercado. Al respecto, se critica la falta de un marco legal más amplio que permita la comercialización de los permisos de emisión de las diferentes industrias en el país ${ }^{21}$.

El medio ambiente es una importante y creciente preocupación en Chile. Dentro de los problemas pendientes está la contaminación del aire en Santiago y la contaminación del agua en diferentes partes del país.

El Cuadro $N^{\circ} 9$ muestra el Índice de Sustentabilidad Ambiental (Environmental Sustainability Index, ESI) del Foro Económico Mundial. Chile se ubica en el lugar 35, que está por debajo del lugar general (22) y detrás de

${ }^{21} \mathrm{Al}$ respecto hay una experiencia exitosa con un mercado de permisos de emisión de material particulado en Santiago (Montero et al., 2002). En el Congreso se está discutiendo una ley al respecto desde 1995. 
CUADRO No 9: I ÍNDICE DE SUSTENTABILIDAD AMBIENTAL

\begin{tabular}{|c|c|c|c|c|c|c|c|c|}
\hline \multicolumn{2}{|c|}{$\begin{array}{l}\text { Ranking/ } \\
\text { País }\end{array}$} & \multirow{2}{*}{$\begin{array}{c}\text { ESI } \\
73,9\end{array}$} & \multicolumn{2}{|c|}{$\begin{array}{l}\text { Ranking/ } \\
\text { País }\end{array}$} & \multirow{2}{*}{$\begin{array}{r}\text { ESI } \\
52,8\end{array}$} & \multicolumn{2}{|c|}{$\begin{array}{l}\text { Ranking/ } \\
\text { País }\end{array}$} & \multirow{2}{*}{$\begin{array}{r}\text { ESI } \\
45,6\end{array}$} \\
\hline 1 & Finlandia & & 49 & Byelarus & & 97 & Cambodia & \\
\hline 2 & Noruega & 73,0 & 50 & Alemania & 52,5 & 98 & Guinea & 45,3 \\
\hline 3 & Suecia & 72,6 & 51 & Papua Nueva Guinea & 51,8 & 99 & Nepal & 45,2 \\
\hline 4 & Canadá & 70,6 & 52 & Nicaragua & 51,8 & 100 & Indonesia & 45,1 \\
\hline 5 & Suiza & 66,5 & 53 & Jordania & 51,7 & 101 & Burkina Faso & 45,0 \\
\hline 6 & Uruguay & 66,0 & 54 & Tailandia & 51,6 & 102 & Sudán & 44,7 \\
\hline 7 & Austria & 64,2 & 55 & Sri Lanka & 51,3 & 103 & Gambia & 44,7 \\
\hline 8 & Islandia & 63,9 & 56 & Kyrgyzstán & 51,3 & 104 & Irán & 44,5 \\
\hline 9 & Costa Rica & 63,2 & 57 & Bosniay Herzegovina & 51,3 & 105 & Togo & 44,3 \\
\hline 10 & Latvia & 63,0 & 58 & Cuba & 51,2 & 106 & El Líbano & 43,8 \\
\hline 11 & Hungría & 62,7 & 59 & Mozambique & 51,1 & 107 & Siria & 43,6 \\
\hline 12 & Croacia & 62,5 & 60 & Grecia & 50,9 & 108 & Costa de Marfil & 43,4 \\
\hline 13 & Botswana & 61,8 & 61 & Túnez & 50,8 & 109 & Zaire & 43,3 \\
\hline 14 & Eslovaquia & 61,6 & 62 & Turquía & 50,8 & 110 & Tajikistán & 42,4 \\
\hline 15 & Argentina & 61,5 & 63 & Israel & 50,4 & 111 & Angola & 42,4 \\
\hline 16 & Australia & 60,3 & 64 & República Checa & 50,2 & 112 & Pakistán & 42,1 \\
\hline 17 & Panamá & 60,0 & 65 & Ghana & 50,2 & 113 & Etiopía & 41,8 \\
\hline 18 & Estonia & 60,0 & 66 & Rumania & 50,0 & 114 & Azerbaiján & 41,8 \\
\hline 19 & Nueva Zelanda & 59,9 & 67 & Guatemala & 49,6 & 115 & Burundi & 41,6 \\
\hline 20 & Brasil & 59,6 & 68 & Malasia & 49,5 & 116 & India & 41,6 \\
\hline 21 & Bolivia & 59,4 & 69 & Zambia & 49,5 & 117 & Filipinas & 41,6 \\
\hline 22 & Colombia & 59,1 & 70 & Argelia & 49,4 & 118 & Uzbekistán & 41,3 \\
\hline 23 & Eslovenia & 58,8 & 71 & Bulgaria & 49,3 & 119 & Ruanda & 40,6 \\
\hline 24 & Albania & 57,9 & 72 & Rusia & 49,1 & 120 & Omán & 40,2 \\
\hline 25 & Paraguay & 57,8 & 73 & Marruecos & 49,1 & 121 & Trinidad y Tobago & 40,1 \\
\hline 26 & Namibia & 57,4 & 74 & Egipto & 48,8 & 122 & Jamaica & 40,1 \\
\hline 27 & Lituania & 57,2 & 75 & El Salvador & 48,7 & 123 & Nigeria & 39,4 \\
\hline 28 & Portugal & 57,1 & 76 & Uganda & 48,7 & 124 & Libia & 39,3 \\
\hline 29 & Perú & 56,5 & 77 & Sudáfrica & 48,7 & 125 & Bélgica & 39,1 \\
\hline 30 & Bhután & 56,3 & 78 & Japón & 48,6 & 126 & Mauritania & 38,9 \\
\hline 31 & Dinamarca & 56,2 & 79 & Rep. Dominicana & 48,4 & 127 & Guinea-Bissau & 38,8 \\
\hline 32 & Laos & 56,2 & 80 & Tanzania & 48,1 & 128 & Madagascar & 38,8 \\
\hline 33 & Francia & 55,5 & 81 & Senegal & 47,6 & 129 & China & 38,5 \\
\hline 34 & Holanda & 55,4 & 82 & Malawi & 47,3 & 130 & Liberia & 37,7 \\
\hline 35 & Chile & 55,1 & 83 & Macedonia & 47,2 & 131 & Turkmenistán & 37,3 \\
\hline 36 & Gabón & 54,9 & 84 & Italia & 47,2 & 132 & Somalia & 37,1 \\
\hline 37 & Irlanda & 54,8 & 85 & Mali & 47,1 & 133 & Nigeria & 36,7 \\
\hline 38 & Armenia & 54,8 & 86 & Bangladesh & 46,9 & 134 & Sierra Leona & 36,5 \\
\hline 39 & Moldova & 54,5 & 87 & Polonia & 46,7 & 135 & Corea del Sur & 35,9 \\
\hline 40 & Congo & 54,3 & 88 & Kazakhstán & 46,5 & 136 & Ucrania & 35,0 \\
\hline 41 & Ecuador & 54,3 & 89 & Kenia & 46,3 & 137 & Haití & 34,8 \\
\hline 42 & Mongolia & 54,2 & 90 & Myanmar (Burma) & 46,2 & 138 & Arabia Saudita & 34,2 \\
\hline 43 & Central Af. Rep. & 54,1 & 91 & Reino Unido & 46,1 & 139 & Iraq & 33,2 \\
\hline 44 & España & 54,1 & 92 & México & 45,9 & 140 & Corea del Norte & 32,3 \\
\hline 45 & Estados Unidos & 53,2 & 93 & Camerún & 45,9 & 141 & Emir. Ár. Unidos & 25,7 \\
\hline 46 & Zimbabwe & 53,2 & 94 & Vietnam & 45,7 & 142 & Kuwait & 23,9 \\
\hline 47 & Honduras & 53,1 & 95 & Benin & 45,7 & & & (5) \\
\hline 48 & Venezuela & 53,0 & 96 & Chad & 45,7 & & & \\
\hline
\end{tabular}

Fuente: Foro Económico Mundial. 
varios países en desarrollo, aunque supera a algunos países desarrolla$\operatorname{dos}^{22}$. Esto sugiere que en Chile aún existe espacio para realizar mejoras en este aspecto.

\subsection{Asuntos específicos al país}

En esta sección discutiré dos factores que considero tienen un impacto significativo en la productividad y que no se han mencionado antes. Estos son la baja participación de las mujeres en la fuerza laboral y la estabilidad política y económica del país.

\section{5.a) Participación de las mujeres en la fuerza de trabajo}

En Chile la participación de las mujeres en la fuerza de trabajo es sólo de 37\% y aunque se ha incrementado durante los últimos años (en 1995 era de 33\%) sigue siendo baja para los estándares latinoamericanos. En los países desarrollados la participación de las mujeres es generalmente sobre el $50 \%$ y en algunos casos sobre el $60 \%$ e incluso $70 \%$. En los países en desarrollo es un poco más baja que ese porcentaje, pero significativamente mayor que para Chile ${ }^{23}$.

La baja participación de las mujeres en la fuerza de trabajo tiene al menos dos consecuencias negativas. En primer lugar las habilidades de una importante fracción de la población no están siendo utilizadas. En segundo lugar, las mujeres pobres participan menos que las ricas, lo que incrementa la desigualdad de ingresos de la familia. Beyer (1997) muestra que las mujeres del quintil más rico participan tres veces más en la fuerza laboral que las mujeres del quintil más pobre.

Hay al menos dos cuestiones que deben recalcarse para incrementar la participación de las mujeres y en especial de las mujeres pobres: primero, para las mujeres pobres es más difícil encontrar a alguien que cuide a sus hijos mientras trabaja, por lo que se requiere una política de cuidado de niños más amplia. Segundo, por la misma razón las mujeres más pobres necesitan mayor flexibilidad en el trabajo (en término de horas, días, vacaciones, lugar de trabajo, etc.).

\footnotetext{
22 EE.UU. está en el lugar 45.

23 Beyer (1997).
} 


\section{5.b.) Estabilidad política y económica}

Desde un punto de vista económico las elecciones políticas en Chile representan, desde el retorno de la democracia en 1990, una competencia entre fuerzas que sostienen que lo mejor para el país es un sistema económico basado en una economía de mercado. Por lo tanto, las diferencias en las políticas económicas de las principales coaliciones no son mayores. Esto ha entregado al país estabilidad y continuidad en las políticas económicas, lo que no es fácil de observar en el resto de América Latina. Esto genera

CUADRO N 10: CHILE: FORTALEZAS Y DEBILIDADES PARA EL CRECIMIENTO DE LA PRODUCTIVIDAD

\begin{tabular}{|c|c|c|c|c|}
\hline & Variable & $\mathrm{F}$ & $\mathrm{D}$ & $\mathrm{N}$ \\
\hline 1) & Investigación y desarrollo & & $\mathrm{x}$ & \\
\hline 2) & Comercio & $\mathrm{x}$ & & \\
\hline 3) & Inversión extranjera directa & $\mathrm{x}$ & & \\
\hline 4) & Capacidad de absorción & & & $\mathrm{x}$ \\
\hline 5) & Calidad del capital humano & & $\mathrm{x}$ & \\
\hline 6) & Cantidad de educación & & & $\mathrm{x}$ \\
\hline 7) & Capital físico & $\mathrm{x}$ & & \\
\hline 8) & Infraestructura & & $\mathrm{x}$ & \\
\hline 9) & Sector financiero & $\mathrm{x}$ & & \\
\hline 10) & Instituciones & $\mathrm{x}$ & & \\
\hline 11) & Política macroeconómica & $\mathrm{x}$ & & \\
\hline 12) & Integración & $\mathrm{x}$ & & \\
\hline 13) & Ubicación geográfica & & $\mathrm{x}$ & \\
\hline 14) & Tamaño & & & $\mathrm{x}$ \\
\hline 15) & Dotación de recursos naturales & & & $\mathrm{x}$ \\
\hline 16) & Competencia & & & $\mathrm{x}$ \\
\hline 17) & Desigualdad del ingreso & & $\mathrm{x}$ & \\
\hline 18) & Medio ambiente & & & $\mathrm{x}$ \\
\hline 19) & Participación femenina en la fuerza de trabajo & & $\mathrm{x}$ & \\
\hline 20) & Estabilidad política & $\mathrm{x}$ & & \\
\hline
\end{tabular}

F: Fortaleza. D: Debilidad. N: Neutral. 
además un buen clima para la inversión, la innovación y el crecimiento de la productividad. Sin embargo, hay que mencionar que esta situación no ha sido así por siempre. Antes de los 70 cada elección implicaba que el nuevo gobierno podía implementar un set de políticas completamente diferente al del gobierno saliente.

\section{Conclusiones}

El crecimiento de la productividad en Chile en los últimos 45 años ha sido muy volátil y ha estado fuertemente correlacionado con el ciclo económico. El período más largo de crecimiento sostenido y elevado de productividad es 1986-1997, que es el que se ha denominado el "período de oro de la economía chilena”. A partir de 1998 se observa una desaceleración de la productividad, que ha tenido como consecuencia un menor crecimiento económico. Sólo en 2004 el crecimiento repunta, pero, aunque aún es muy temprano para evaluarlo, parece estar más ligado a un mejoramiento extraordinario de las condiciones externas que a un incremento sostenido de la productividad.

Hay una serie de factores que han influido en una u otra dirección en el desempeño de la productividad en Chile en este período. El Cuadro $\mathrm{N}^{\circ} 10$ es una síntesis de las diferentes variables analizadas para el caso chileno. De acuerdo a la discusión previa, se clasifican dichas variables en aquellas que, dadas las condiciones actuales de la economía chilena, son consideradas como fortalezas, debilidades o neutrales en materia de productividad. Para retomar el proceso de crecimiento es necesario enfatizar reformas que permitan lograr mejorías en aquellos aspectos en los cuales el país hoy está relativamente más débil.

\section{REFERENCIAS}

Acemoglu, D., S. Johnson, y J. A. Robinson (2001): “The Colonial Origins of Comparative Development: An Empirical Investigation”. American Economic Review, 91(5): 1369-1401.

Alesina, A. y D. Rodrick (1994): “Distributive Politics and Economic Growth”. Quarterly Journal of Economics, Vol. 109, No 2, mayo.

Aschauer, D. (1989): “Is Public Expenditure Productive?” Journal of Monetary Economics, 23, pp. 177-200.

Banco Central de Chile (2005): Informe de Política Monetaria. Mayo.

Barro, R. (1997): "Determinants of Economic Growth: A Cross Country Empirical Study". NBER Working Paper $N^{\circ} 5698$. 
Barro, R. (1999): "Determinants of Economic Growth: Implications of the Global Evidence for Chile”. Cuadernos de Economía, Año 36 Vol. 107, pp. 443-478.

Barro, R. y J. W. Lee (2000): "International Data on Educational Attainment: Updates and Implications”. NBER Working Paper Series $N^{\circ}$ 7911, National Bureau of Economic Research, Cambridge, MA.

Beyer, H. (1997): “Distribución del Ingreso: Antecedentes para la Discusión”. Estudios Públicos, 65, Verano.

Beyer, H. (2000): "Educación y Desigualdad de Ingresos: Una Nueva Mirada”. Estudios Públicos, 77, verano.

Beyer, H. y R. Vergara (2002): "Productivity and Economic Growth: The Case of Chile". En Loayza y Soto (editores), Economic Growth: Sources, Trends and Cycles. Santiago: Banco Central de Chile.

Calderón, C. y L. Servén (2003): “The Output Cost of Latin America’s Infraestructure Gap”. En W. Easterly y L. Servén (editores), The Limits of Stabilization: Infraestructure, Public Deficits, and Growth in Latin America. Stanford University Press y the World Bank, pp. 95-118.

De Gregorio, J. (1992): “Economic Growth in Latin America”. Journal of Development Economics, $\mathrm{N}^{\circ} 39$, pp. 59-84.

De Gregorio, J. (2004): "Economic Growth in Chile: Evidence, Sources and Prospects”. Documento de Trabajo 298, Banco Central de Chile, Santiago.

De Gregorio, J. y J. W. Lee (2004): "Growth and Adjustment in East and Latin America”. Economia.

Del Fávero, G. y R. Katz (2001): “Gestión Ambiental en Chile”. En F. Larraín y R. Vergara (editores), La Transformación Económica de Chile. Santiago: Centro de Estudios Públicos.

Easterly, W. (1993): “How Much Do Distorsions Affect Growth?”. Journal of Monetary Economics, 32 (2), 187-212.

Eyzaguirre, N. y O. Larrañaga (1990): "Macroeconomía de las Operaciones Cuasifiscales en Chile”. Working Paper, ILADES/Georgetown University, Santiago.

Eyzaguirre, B. y L. Fontaine (2001): "Una Estructura que Presione a las Escuelas a Hacerlo Bien”. En Harald Beyer y Rodrigo Vergara (editores), ¿Qué Hacer Ahora? Propuestas para el Desarrollo. Santiago: Centro de Estudios Públicos.

Fischer, S. (1993): "The Role of Macroeconomic Factors in Growth”. Journal of Monetary Economics, Vol. 32, pp. 485-512.

Gallego y Loayza (2002): "The Golden Period for Growth in Chile: Explanations and Forecasts”. En Loayza y Soto (editores), Economic Growth: Sources, Trends and Cycles. Santiago: Banco Central de Chile.

Hachette, D. (2001a): "La Reforma Comercial”. En F. Larraín y R. Vergara (editores), La Transformación Económica de Chile. Santiago: Centro de Estudios Públicos.

Hachette, D. (2001b): “Privatizaciones: Reforma Estructural pero Inconclusa”. En F. Larraín y R. Vergara (editores), La Transformación Económica de Chile. Santiago: Centro de Estudios Públicos.

Heckman, J., y C. Pagés (2000): "The Cost of Job Security Regulation: Evidence from Latin American Labor Markets”. Mimeo, mayo.

Hsieh, Chang-Tai y J. Parker (2001): "Taxes and Growth in a Financially Underdeveloped Country: Explaining the Chilean Investment Boom”. Mimeo, Princeton University, junio. 
Kaufmann, D., A. Kraay y P. Zoido-Lobatón (1999): “Governance Matters”. PRD Working Paper $\mathrm{N}^{\circ}$ 2196, The World Bank Institute.

Krueger, A. (1990): “Government Failures in Development”. Journal of Economic Perspectives, 4 (marzo), 9-23.

Lane, P. y A. Tornell (1996): "Power, Growth and the Voracity Effect”. Journal of Economic Growth, 1, pp. 213-241.

Larraín, F. y R. Vergara (1992): “Distribución del Ingreso, Inversión y Crecimiento”. Cuadernos de Economía, No 87, agosto.

Larraín, F. y R. Vergara (1993): "Investment and Macroeconomic Adjustment: The Case of East Asia”. En Luis Serven y Andrés Solimano (editores), Striving for Growth: the Role of Capital Formation, Washington D.C.: World Bank.

Larraín, F. y R. Vergara (2001): "La Transformación Económica de Chile”. Santiago: Centro de Estudios Públicos.

Lederman, D. y W. Maloney (2003): "R\&D and Development”. Mimeo. Banco Mundial.

Levine, R (2005): "Finance and Growth: Theory and Evidence”. En P. Aghion y S. Durlauf (editores), Handbook of Economic Growth. North Holland.

Ministerio de Hacienda (2004): "Estado de la Hacienda Pública 2004”. Ministerio de Hacienda, Chile.

Marcel, M., M. Tokman, R. Valdés y P. Benavides (2001): "Balance Estructural del Gobierno Central: Metodología y Estimaciones para Chile: 1987-2000”. Estudios de Finanzas Públicas. Dirección de Presupuestos, Ministerio de Hacienda, septiembre.

Montero, J. P., J. M. Sánchez y R. Katz (2002): “The Market Based Environmental Policy Experiment in Chile". The Journal of Law and Economics, Volume XLV(1), abril.

North, D. (1992): Institutions, Institutional Change and Economic Performance. Cambridge: Cambridge University Press.

Paredes, R. (2001a): "Regulación Económica en Chile: La Opción por un Enfoque no Estructural”. En F. Larraín y R. Vergara (editores), La Transformación Económica de Chile. Santiago: Centro de Estudios Públicos.

Paredes, R. (2001b): "Desafíos para la Institucionalidad Antimonopolios en Chile”. En Harald Beyer y Rodrigo Vergara (editores), ¿Qué Hacer Ahora? Propuestas para el Desarrollo. Santiago: Centro de Estudios Públicos.

Rojas, P., E. López y S. Jiménez (1997): "Determinantes del Crecimiento y Estimación del Producto Potencial en Chile: El Rol del Comercio Internacional”. En F. Morandé y R. Vergara (editores), Análisis Empírico del Crecimiento en Chile. Santiago: CEP/ ILADES, 67-100.

Rodríguez, F. y J. Sachs (1999): "Why do Resource-Abundant Economies Grow More Slowly?”. Journal of Economic Growth, 4, 277-303.

Sachs, J. y A. Warner (1995): "Natural Resource Abundance and Economic Growth". NBER Working Paper 5398.

Servén, L. y A. Solimano (1993): "Private Investment and Macroeconomic Investment: A Survey”. En L. Serven y A. Solimano (editores), Striving for Growth after Adjustment: The Role of Capital Formation. Washington D.C.: The World Bank, pp. 11-30.

Vergara, R. (2002): "Política y Sostenibilidad Fiscal en Chile”. Estudios Públicos, N 88, primavera.

Vergara, R. (2003): "Reform, Growth and Slowdown: Lessons from Chile”. En Grzegorz Kolodko (editor), Emerging Market Economies. Ashgate Publishing. 
Vergara, R. (2004): “Taxation and Private Investment: Evidence for Chile”. Documento de Trabajo No 268, Universidad Católica de Chile.

Vergara, R. (2005): "Productivity Performance in Developing Countries: The Case of Chile”. Artículo preparado para la Organización para el Desarrollo Industrial de las Naciones Unidas (UNIDO), junio.

Vergara, R. y R. Rivero (2005): "Productividad Sectorial en Chile: 1986-2001”. Documento de Trabajo $\mathrm{N}^{\circ}$ 286, Universidad Católica de Chile. 